2017-12-01

\title{
Microstructural Evaluation of Hydrogen Embrittlement and Successive Recovery in Advanced High Strength Steel
}

Quentin Scott Allen

Brigham Young University

Follow this and additional works at: https://scholarsarchive.byu.edu/etd

Part of the Mechanical Engineering Commons

\section{BYU ScholarsArchive Citation}

Allen, Quentin Scott, "Microstructural Evaluation of Hydrogen Embrittlement and Successive Recovery in Advanced High Strength Steel" (2017). All Theses and Dissertations. 6617.

https://scholarsarchive.byu.edu/etd/6617 
Microstructural Evaluation of Hydrogen Embrittlement and Successive

Recovery in Advanced High Strength Steel

Quentin Scott Allen

A thesis submitted to the faculty of

Brigham Young University

in partial fulfillment of the requirements for the degree of

Master of Science

Tracy W. Nelson, Chair

David T. Fullwood

Eric R. Homer

Department of Mechanical Engineering

Brigham Young University

Copyright (C) 2017 Quentin Scott Allen

All Rights Reserved 


\author{
ABSTRACT \\ Microstructural Evaluation of Hydrogen Embrittlement and Successive \\ Recovery in Advanced High Strength Steel \\ Quentin Scott Allen \\ Department of Mechanical Engineering, BYU \\ Master of Science
}

Advanced high strength steels (AHSS) have high susceptibility to hydrogen embrittlement, and are often exposed to hydrogen environments in processing. In order to study the embrittlement and recovery of steel, tensile tests were conducted on two different types of AHSS over time after hydrogen charging. Concentration measurements and hydrogen microprinting were carried out at the same time steps to visualize the hydrogen behavior during recovery. The diffusible hydrogen concentration was found to decay exponentially, and equations were found for the two types of steel. Hydrogen concentration decay rates were calculated to be $-0.355 / \mathrm{hr}$ in TBF steel, and $-0.225 / \mathrm{hr}$ in DP. Hydrogen concentration thresholds for embrittlement were found to be $1.04 \mathrm{~mL} / 100 \mathrm{~g}$ for TBF steel, and $0.87 \mathrm{~mL} / 100 \mathrm{~g}$ for DP steel. TBF steel is predicted to recover from embrittlement within 4.1 hours, compared to 7.2 hours in DP steel. A two-factor method of evaluating recovery from embrittlement, requiring hydrogen concentration threshold and decay rate, is explained for use in predicting recovery after exposure to hydrogen. Anisotropic hydrogen diffusion rates were also observed on the surface of both steels for a short time after charging, as hydrogen left the surface through $<001>$ and $<101>$ grains faster than grains with $<111>$ orientations. This could be explained by differences in surface energies between the different orientations.

Keywords: steel, AHSS, HMT, OIM, hydrogen embrittlement, recovery, diffusion, crystallographic orientation 


\section{ACKNOWLEDGEMENTS}

This work was partially funded under a research grant from Arcelor Mittal. I would like to show my gratitude to Dr. Nelson and Dr. Fullwood for helping me get started in academic research. I especially appreciate Dr. Nelson's flexibility and support as my advisor. I am grateful to Jonathan Mortensen for his help starting research together, and for creating a fun research environment. I am grateful to Paul Minson and Jeff Farrer of the BYU Microscopy department for the use of their equipment, and the hours spent training me on the best methods for evaluating my results. I would also like to thank the many other students and professors involved in materials research with whom I interacted at BYU. We shared many ideas, joys, disappointments, and hours of polishing together. The discussions we shared helped shape the path of this research. I am grateful to my wife, parents, and siblings for their patience, continuous prayers, love, and support as I completed this thesis. Their help and encouragement was invaluable. I also wish to thank my Father in Heaven for the quiet moments of inspiration that helped lead to the completion of this project. 


\section{TABLE OF CONTENTS}

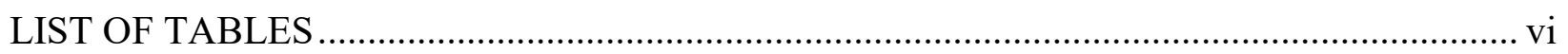

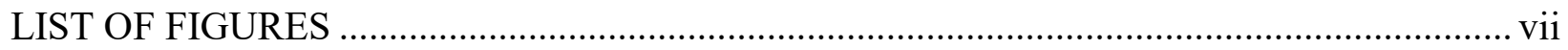

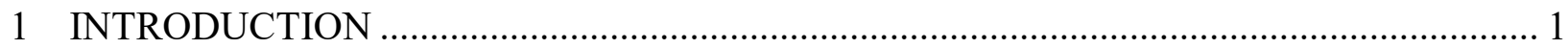

1.1 Advanced High Strength Steel ............................................................................... 1

1.2 Hydrogen Embrittlement of AHSS ……………….......................................... 1

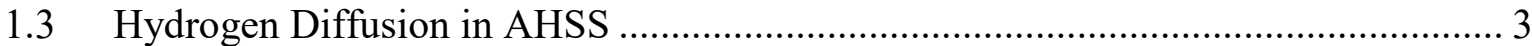

1.3.1 Current Hydrogen Research ...................................................................... 3

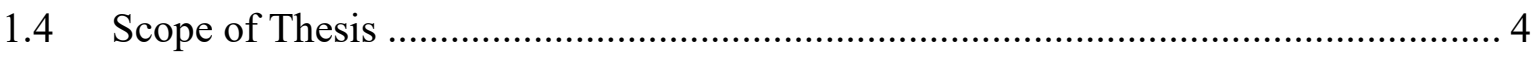

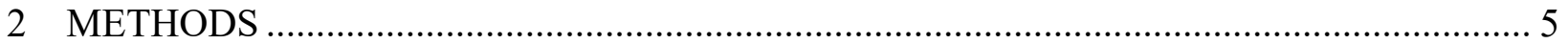

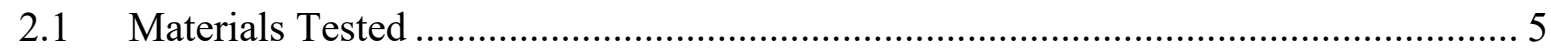

2.2 Hydrogen Charging ............................................................................................ 5

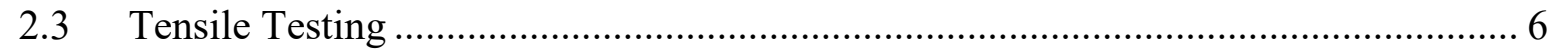

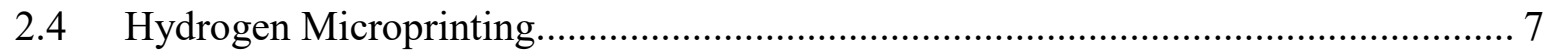

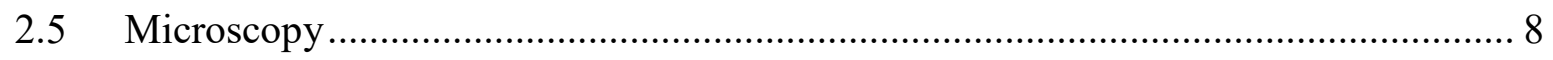

2.6 Hydrogen Measurement ................................................................................... 10

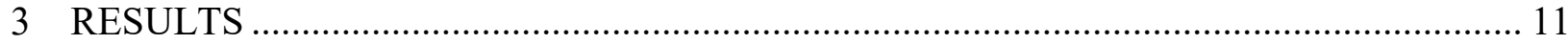

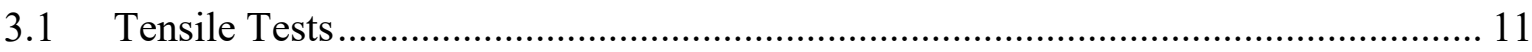

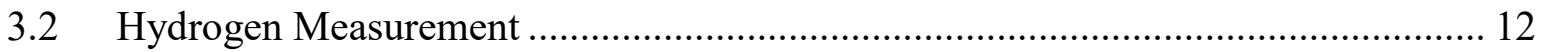

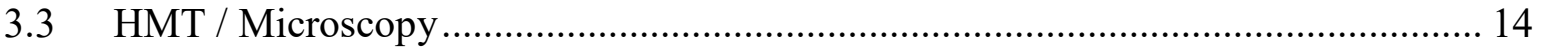

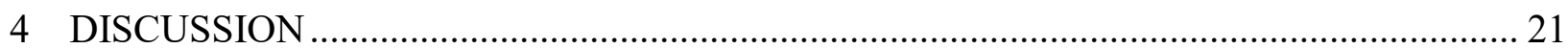

4.1 Ductility as a Function of Hydrogen Concentrations ................................................ 21

4.2 Anisotropic Orientation Dependence ...................................................................... 23

4.3 Resistance to Hydrogen Embrittlement ....................................................................... 24

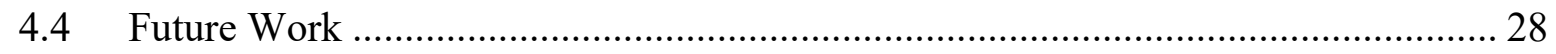

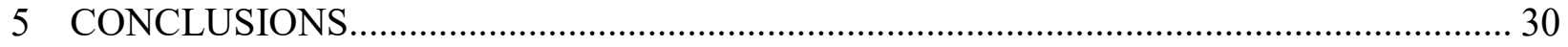

$5.1 \quad$ DP Steel Response to Hydrogen ........................................................................ 30

5.2 TBF Steel Response to Hydrogen ………………………………………….... 30

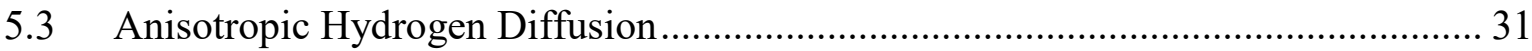

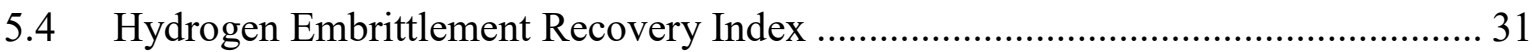




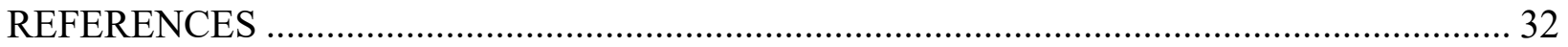

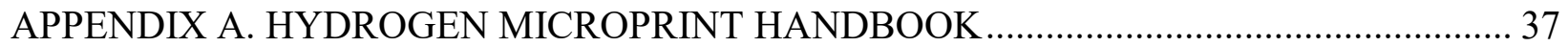

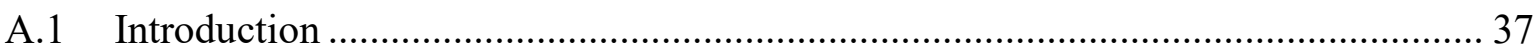

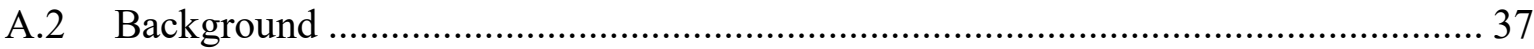

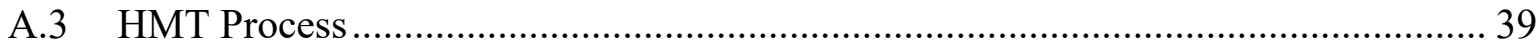

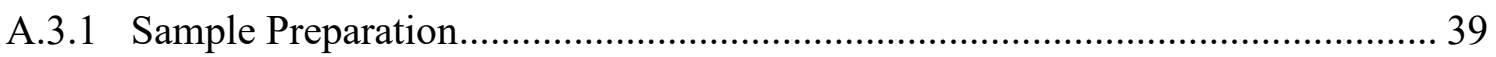

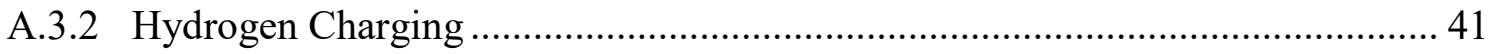

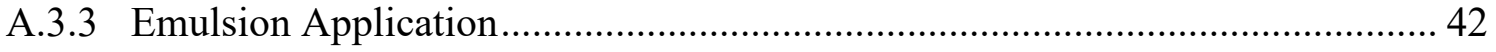

A.3.4 Emulsion Fixing …………………………………...................................... 45

A.3.5 Microprint Evaluation ................................................................................. 45

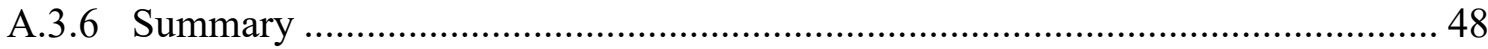

A.4 Scholarly Articles .............................................................................................. 49

A.5 Hydrogen Charging Table ……………………….......................................... 49

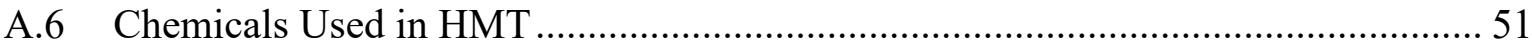

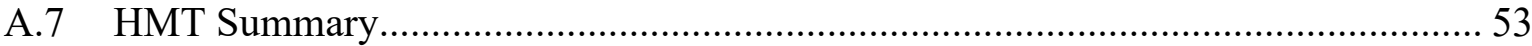

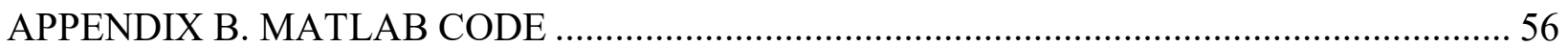




\section{LIST OF TABLES}

Table 2-1: Alloying element compositions of the steels tested .............................................. 5

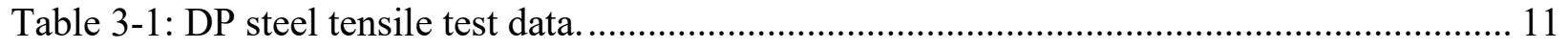

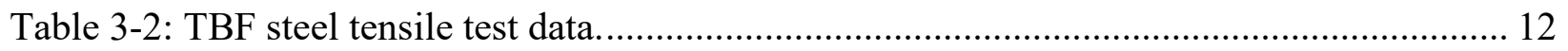

Table 3-3: Orientation and silver coverage of selected grains of DP steel .............................. 15

Table 3-4: Orientation and silver coverage of selected grains of TBF steel............................ 15

Table 3-5: Coefficient values for hydrogen flux best-fit curves ......................................... 18

Table 4-1: Surface energies of ferrite crystal orientations..................................................... 24 


\section{LIST OF FIGURES}

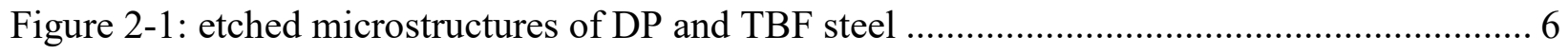

Figure 2-2: the dimensions of the tensile specimens used in this study ................................. 7

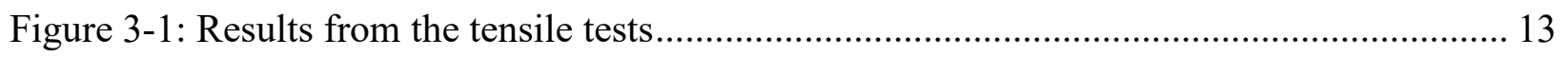

Figure 3-2: Diffusible hydrogen concentration of DP and TBF steel.................................. 14

Figure 3-3: Microprint and EBSD IPF maps of DP steel ............................................... 16

Figure 3-4: Microprint and EBSD IPF maps of TBF steel ............................................ 17

Figure 3-5: Representative hydrogen flux as a function of time .......................................... 19

Figure 4-1: Ductility as a function of hydrogen concentration............................................ 21

Figure 4-2: Microprint of TBF steel 100 hours after charging ........................................... 23

Figure 4-3: The hydrogen recovery of the tested steels ................................................. 26

Figure 4-4: A theoretical hydrogen recovery model....................................................... 27 


\section{INTRODUCTION}

\subsection{Advanced High Strength Steel}

Advanced high strength steels (AHSS) were designed for the automotive industry to combine high strength with greater ductility than typical steels. AHSS contain complex microstructures that allow for their improved properties [1]. Two important types of AHSS are dual phase (DP), and transformation-induced plasticity (TRIP) steels. DP steel consists of small, hard islands of fine martensite lathes that strengthen a soft ferrite matrix, resulting in a high strength steel with a surprising amount of ductility. TRIP steels are strengthened under a similar mechanism, with hard martensite and bainite phases in the ferrite matrix [2]. TRIP steels also contain retained austenite, which contributes to ductility by transforming to martensite under an applied stress. The great strength and formability of automotive AHSS make them prime materials for lighter, safer vehicles.

\subsection{Hydrogen Embrittlement of AHSS}

One concern for the widespread use of AHSS is their propensity to hydrogen embrittlement (HE) [1]. High hydrogen concentration reduces the ductility and toughness of steel, leading to unpredictable failures [3]-[6]. In general, the embrittlement effect is more pronounced in higher-strength steels [7]-[9]. Hydrogen can enter steel during corrosion, or processing steps like welding, painting, plating, and galvanizing [1], [10]. Extremely high 
concentrations of hydrogen can cause the formation of cracks along grain boundaries or other lattice defects even without an applied stress [11], [12]. Delayed cracking can occur long after processing, as hydrogen diffuses to areas of residual stresses [13]. Methods to mitigate HE are commonly used in steel processing, but the complex microstructure of AHSS present a new set of challenges.

HE is typically measured by quantifying the loss of ductility for materials charged with hydrogen. ASTM G142 outlines procedures for performing tensile tests on a base material, and again when charged with hydrogen. A material's susceptibility to hydrogen is thus determined by how drastically strength and ductility are reduced. Similarly, resistance to HE is determined by showing less ductility loss compared to another material at similar hydrogen exposure [14]. Aside from tensile tests, ductility can also be measured with drawing, punching, or bending tests [15]-[17]. These test methods quantify the severity of embrittlement, but only at the concentrations and times tested.

The time to recover from hydrogen embrittlement is an important factor in industry. In an ideal production line, any hydrogen uptake from one processing step will be depleted before the next processing step begins. There are a few standard tests that are time-sensitive. ASTM F519 and A1030 describe constant force methods to determine a material's susceptibility to delayed fracture. Threshold hydrogen concentrations can be determined such that there is no danger of delayed cracking if hydrogen concentrations are kept below the threshold [18], [19]. If hydrogen content exceeds the threshold, however, recovery time after hydrogen uptake is still unknown. In-depth knowledge of recovery from HE is needed. 


\subsection{Hydrogen Diffusion in AHSS}

Hydrogen's interaction with steel is complicated and difficult to study. Absorbed hydrogen diffuses through the steel matrix, especially towards areas of high stress or strain [8], [13]. Packing distance between atoms affects diffusion speed and saturation limits. Extra space from dislocations, voids, and grain boundaries can be both traps and pathways for diffusing hydrogen [9], [11], [20]. Austenite has a higher hydrogen solubility limit but a slower diffusion rate than ferrite or martensite, making it an effective hydrogen trap [5], [20]-[25]. Recent research has indicated that crystalline orientations have an effect on hydrogen diffusion rates [26], and resistance to HE [12].

\subsubsection{Current Hydrogen Research}

Hydrogen-metal interactions remain an active area of research. There are at least 4 distinct theories on the mechanisms of HE [27]-[30], though a combination of multiple theories may be most accurate [31]-[33]. There has been great progress in modelling and simulating the diffusion of hydrogen in steels [9], [34]-[40]. Experimental methods to view and characterize actual locations of hydrogen concentrations and the effects on properties over time are still needed to help inform the mathematical simulations.

Common experimental techniques such as thermal desorption analysis and permeation cells measure amounts of hydrogen, but without information about location [41]-[43]. Scanning Kelvin probe force microscopy and the hydrogen microprint technique (HMT) are two methods that can detect relative amounts of hydrogen at the surface of a sample [44], [45]. In HMT, hydrogen diffusing out of the steel reacts with a silver bromide ( $\mathrm{AgBr})$ emulsion, reducing solid silver particles on the surface [45]-[48]. HMT has been used to show preferred pathways of 
hydrogen diffusion along areas of high deformation and dislocation density [6], [49]. A modified version of HMT showed diffusion along high angle grain boundaries [50]. More of these studies of the interaction of hydrogen with specific microstructures is needed to better understand HE.

\subsection{Scope of Thesis}

To study the time-dependent behavior of hydrogen in AHSS, the hydrogen microprint technique is combined with orientation imaging microscopy (OIM) to visualize hydrogen diffusion in terms of the underlying microstructure. OIM is a technique where electron backscatter diffraction (EBSD) patterns are used to identify the orientation of atomic planes in a sample [51], [52]. Performing OIM and HMT on the same location of a steel sample reveals which phases, grain boundaries, and orientations diffuse and trap the most hydrogen. Tensile tests and hydrogen concentration measurements allow for quantification of hydrogen embrittlement over time. This study will combine the microstructural data of HMT and EBSD with tensile tests at various times to show hydrogen's effect on AHSS ductility over time. This data will give insight to the selection of automotive steels and prediction of $\mathrm{HE}$ recovery times needed for different production lines. 


\section{METHODS}

\subsection{Materials Tested}

Two types of AHSS were investigated: DP 980 and TBF 980 (a TRIP steel). Both steels were rated for a strength of $980 \mathrm{MPa}$. Table 2-1 shows the nominal components, and Figure 2-1 shows scanning electron microscope (SEM) pictures of the microstructures of the two types of steel.

Table 2-1: Alloying element compositions of the steels tested in wt\% [2].

\begin{tabular}{l|ccc}
\hline Steel Type & $C$ & $S i$ & $M n$ \\
\hline DP 980 & 0.097 & 0.015 & 2.349 \\
TBF 980 & 0.16 & 1.3 & 2.2 \\
\hline
\end{tabular}

\subsection{Hydrogen Charging}

An electrochemical hydrogen charging method was employed to saturate the steels with hydrogen. Cathodic charging occurred in a $0.5 \mathrm{M}$ sulfuric acid solution with $0.4 \mathrm{~g} / \mathrm{L}$ of the electrolyte thiourea and a constant current density of $16.7 \mathrm{~mA} / \mathrm{cm}^{2}$. The DP steel was charged for 90 minutes, and the TBF steel for 120 minutes. 


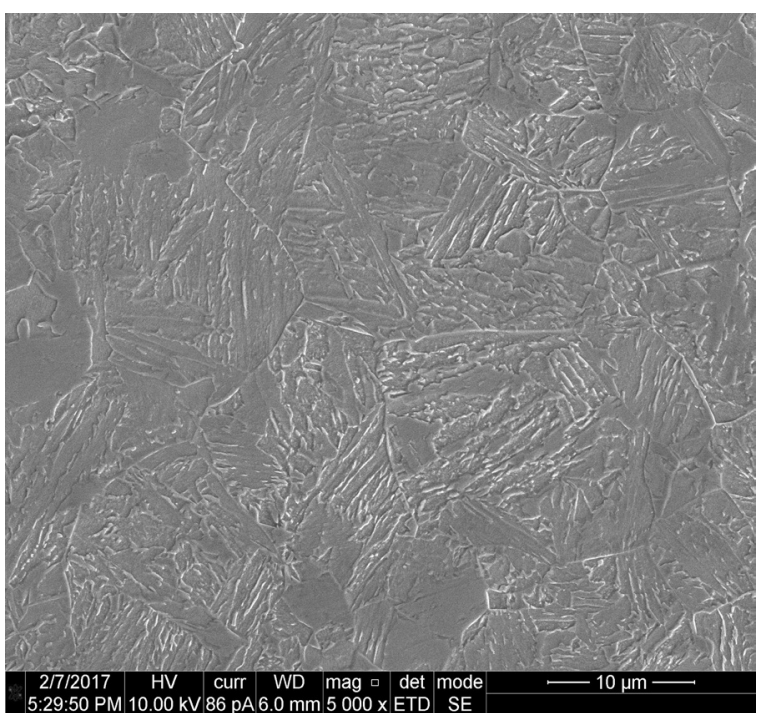

$\mathbf{a}$

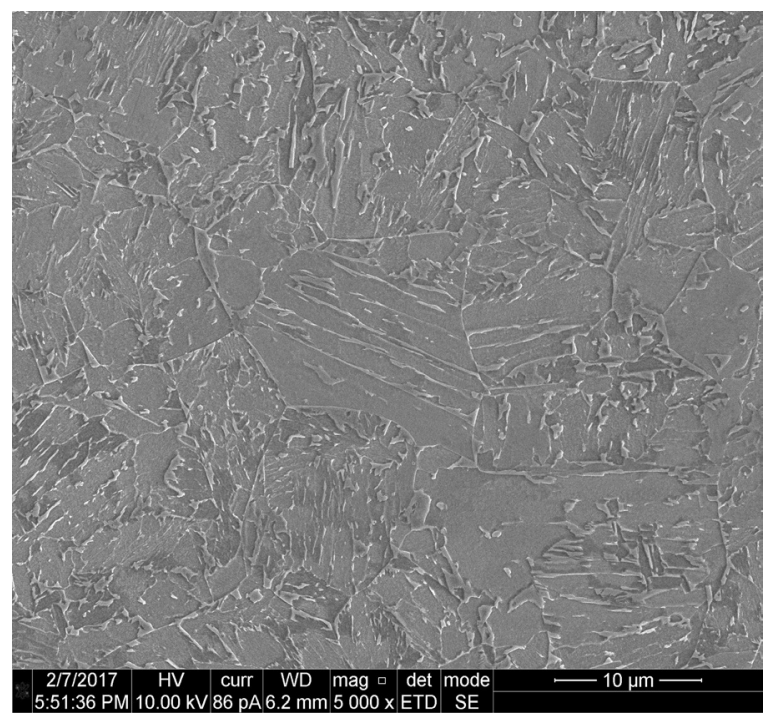

b

Figure 2-1: etched microstructures of a) DP and b) TBF steel. Notice the finer lath structure of the DP steel and the greater variety of hardening precipitates in the TBF.

\subsection{Tensile Testing}

Tensile tests were conducted to show the effects of hydrogen on DP and TBF steel properties. Slow strain rates are known to accentuate the loss of ductility [7], [53], [54]. ASTM G129 was consulted in determining an appropriate strain rate of $10^{-4} / \mathrm{s}$ for the embrittlement tensile tests. ASTM E8 was referenced in creating the dog-bone dimensions shown in Figure 2-2. The tensile specimens were cut out of $1.6 \mathrm{~mm}$ thick sheets using a water-jet cutter, with the rolling direction along the tensile axis. Testing was performed at 1, 2, 5, 10, 25, and 100 hours after hydrogen charging to view how hydrogen embrittlement recovers over time. The yield strength, ultimate tensile strength (UTS), and elongation at failure were recorded for each specimen, along with the recovery time after charging. 


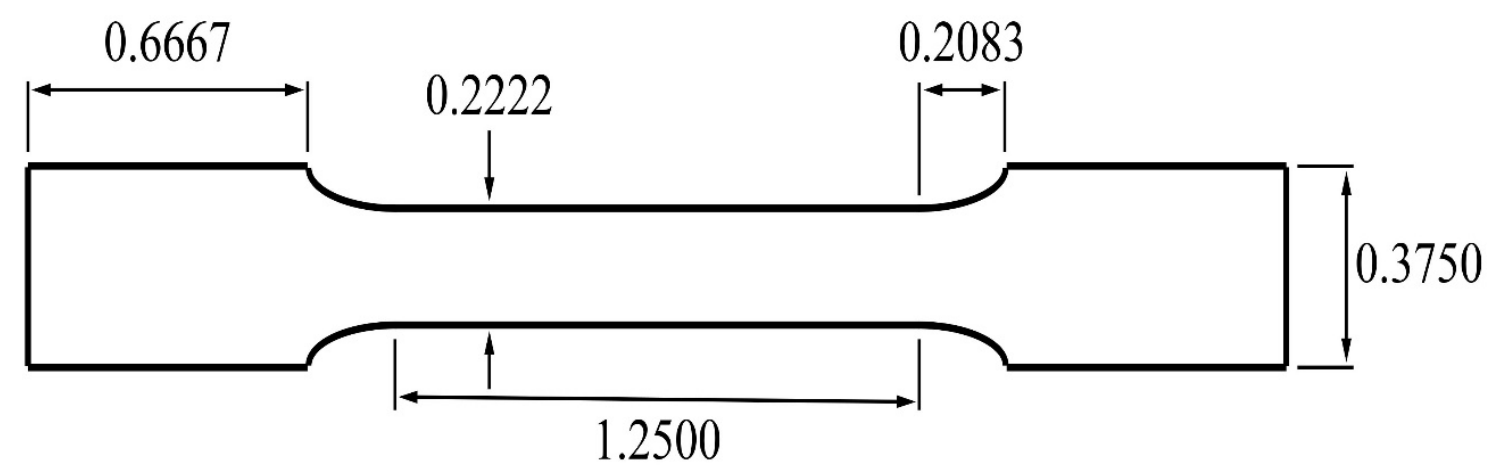

Figure 2-2: the dimensions of the tensile specimens used in this study (all units in inches).

\subsection{Hydrogen Microprinting}

High traffic hydrogen exit locations were marked with HMT. Coupons of the two types of steel approximately $2 \mathrm{~cm}$ by $1.5 \mathrm{~cm}$ were prepared for HMT and OIM by standard metallographic grinding and polishing. The final polishing step was a water-free suspension of $0.05 \mu \mathrm{m}$ colloidal silica on a vibratory polisher for 2 hours. The samples were then charged and allowed to recover the same amounts of time $(1,2,5,10,25,100$ hours) before microprinting. Samples were given an additional light polish with $0.1 \mu \mathrm{m}$ diamond paste after charging and about 10-15 minutes prior to microprinting to remove any artifacts from the charging and clear the sample surface of any hydrogen that had previously evolved and collected on the surface.

Microprinting was performed in a darkroom, where the silver bromide emulsion was prepared by combining $20 \mathrm{~mL}$ of a $1.4 \mathrm{M}$ sodium nitrite solution with $10 \mathrm{~g}$ silver bromide gel. Ag-Plus silver bromide emulsion from Rockland Colloid was found to give comparable results to the Ilford L4 emulsion typically used for microprinting, while being significantly less expensive. 
A thin film of emulsion was placed over the sample using a wire loop and allowed to develop on the sample for 20 minutes. Shorter development times were needed for the samples microprinted 1 hour after charging in order to characterize differences in the hydrogen flux between grains. The relative humidity in the darkroom was kept at $80 \%$ to prevent the emulsion from drying out. After development, the samples were dipped in formalin for 3 seconds and placed in a solution of $1.4 \mathrm{M}$ sodium nitrite combined with $0.6 \mathrm{M}$ sodium thiosulfate to wash away unreacted silver bromide. After 5 minutes of light agitation in the thiosulfate fixing solution, the sample was moved to a bath of hot $\left(\sim 80^{\circ} \mathrm{C}\right)$ distilled water. Soap was added to the bath, which was placed in an ultrasonic cleaner for 2 minutes to wash away the top layer of gelatin. Samples were dried with methanol and compressed air to protect from corrosion. A hydrogen microprinting manual produced for the purpose of training new researchers on how to perform HMT is included in Appendix A.

\subsection{Microscopy}

Microprinted samples were viewed in the SEM. A focused ion beam (FIB) was used to create fiducial marks near areas with good microprinting. The marked areas were imaged with a back-scatter electron (BSE) detector using an accelerating voltage of $20 \mathrm{kV}$. In BSE images, silver shows up lighter than the steel substrate. Energy-dispersive x-ray spectroscopy (EDS) with an accelerating voltage of $20 \mathrm{kV}$ and working distance of $5 \mathrm{~mm}$ was used to verify that the small spheres apparent on the surface were silver, and to quantify the silver coverage. Silver quantification was completed by scanning 3 regions with varying amounts of silver near each fiducial mark. The background signal was subtracted off of the resulting X-ray energy spectra, and the number of $\mathrm{x}$-ray counts at the characteristic energy of silver (2.99 $\mathrm{keV})$ were divided by 
the counts at the iron characteristic level $(6.40 \mathrm{keV})$ to obtain a non-dimensional peak-height ratio that could be compared across samples. The three levels of silver coverage were used as a comparison standard to determine the X-ray elemental quantification of silver for any other grain at that location given the percentage of silver particles (lighter pixels) in a selected area of the BSE image.

After imaging, the microprinting was cleaned off the samples with a warm soap water bath in an ultrasonic cleaner until the film begins to separate from the sample. The samples were taken back to the SEM for OIM analysis in the locations marked by the FIB fiducial marks. 55 $\mu \mathrm{m}$ x $55 \mu \mathrm{m}$ EBSD scans were performed using an accelerating voltage of $20 \mathrm{kV}$, and a $0.15 \mu \mathrm{m}$ step size.

A Matlab code was developed to analyze the different microprint images. A specific grain could be selected in both the EBSD inverse pole figure (IPF) image and the BSE microprint picture. Relevant grain data from the EBSD scan, and the percentage of the grain covered with silver particles in the BSE image was recorded for correlation. This Matlab code is included in Appendix B. This silver percentage was converted to a silver-to-iron peak-height ratio using the comparison standards created from the 3 data points at each fiducial mark.

It can be assumed that the amount of silver on the microprint surface is proportional to the hydrogen flux during the development time, until all available silver particles have been developed. The silver-to-iron peak-height ratio is thus a non-dimensional measure of silver proportional to the amount of hydrogen that passed through the surface at that location. The representative hydrogen flux values reported in Section 2 were obtained by dividing the X-ray peak-height ratio of each grain by the development time that the $\mathrm{AgBr}$ sat on the surface. While 
the actual value of hydrogen flux is still unknown, the relative amounts of hydrogen flux are clearly discernable. Multiple grains from each orientation were analyzed at each fiducial mark, and averaged to get the results reported in Section 2.

\subsection{Hydrogen Measurement}

Measurement of the actual hydrogen concentration was performed using the hot glycerol method and following procedures outlined in ANSI/AWS A4.3. The diffusible hydrogen content in both types of steel were measured immediately after charging, and at 1, 2, 5, 10, and 25 hours after charging. Diffusible hydrogen leaving the sample displaced a measurable volume of glycerin. The mass of the steel was measured to report the hydrogen content in units of $\mathrm{mL} \mathrm{H} /$ $100 \mathrm{~g}$ steel. 


\section{RESULTS}

\subsection{Tensile Tests}

Tensile tests showed that hydrogen reduced the ductility of DP and TBF steel without affecting the yield or ultimate tensile strength. Complete results of the tensile tests are compiled in Table 3-1 and Table 3-2. Figure 3-1 shows the strength and ductility as a function of postcharging recovery time. The ductility of DP samples dropped by $43.1 \%$ when tested 1 hour after hydrogen charging, while the TBF steel ductility dropped by $28.3 \%$ at the same time interval.

Table 3-1: DP steel tensile test data.

\begin{tabular}{l|ccc}
\hline Time After Charging $(\mathrm{hr})$ & Yield Strength $(\mathrm{MPa})$ & UTS $(\mathrm{MPa})$ & Ductility at failure (\%) \\
\hline 1 & 817 & 1005 & 8.4 \\
2 & 800 & 1018 & 9.7 \\
5 & 783 & 988 & 12.9 \\
10 & 793 & 1009 & 14.0 \\
25 & 800 & 1004 & 14.7 \\
100 & 776 & 1017 & 13.7 \\
\hline Uncharged & 787 & 1027 & 14.7 \\
\hline
\end{tabular}


Table 3-2: TBF steel tensile test data.

\begin{tabular}{l|ccc}
\hline Time After Charging $(\mathrm{hr})$ & Yield Strength (MPa) & UTS $(\mathrm{MPa})$ & Ductility at failure (\%) \\
\hline 1 & 790 & 991 & 8.7 \\
2 & 770 & 980 & 9.8 \\
5 & 767 & 991 & 13.0 \\
10 & 765 & 995 & 13.6 \\
25 & 762 & 997 & 12.8 \\
100 & 773 & 990 & 13.0 \\
\hline Uncharged & 754 & 979 & 12.2 \\
\hline
\end{tabular}

Both types of steel recovered ductility over time. Hydrogen diffused out of the specimens until the concentration fell to levels such that the base metal ductility fully recovered. DP steel samples tested 1,2, and 5 hours after charging showed reduced ductility, while those tested 10 or more hours post-charging displayed comparable ductility to that of the base metal (Figure 3-1c). In TBF steel, only samples tested at 1 and 2 hours after charging were brittle, and samples tested 5 hours or longer after charging had recovered the ductility of the uncharged specimens (Figure 3-1d). A critical hydrogen concentration threshold where ductility returns is reached between 2 and 5 hours after charging in the TBF steel, and between 5 and 10 hours in the DP steel.

\subsection{Hydrogen Measurement}

The diffusible hydrogen content was measured immediately after charging, and at 1, 2, 5, 10 , and 25 hours post-charging. Both types of steel reached a maximum hydrogen level of 4.4 $\mathrm{mL} / 100 \mathrm{~g}$ during the hydrogen charging. After removal from the charging bath, hydrogen content in the steels decreases with an exponential decay, as shown in Figure 3-2. 


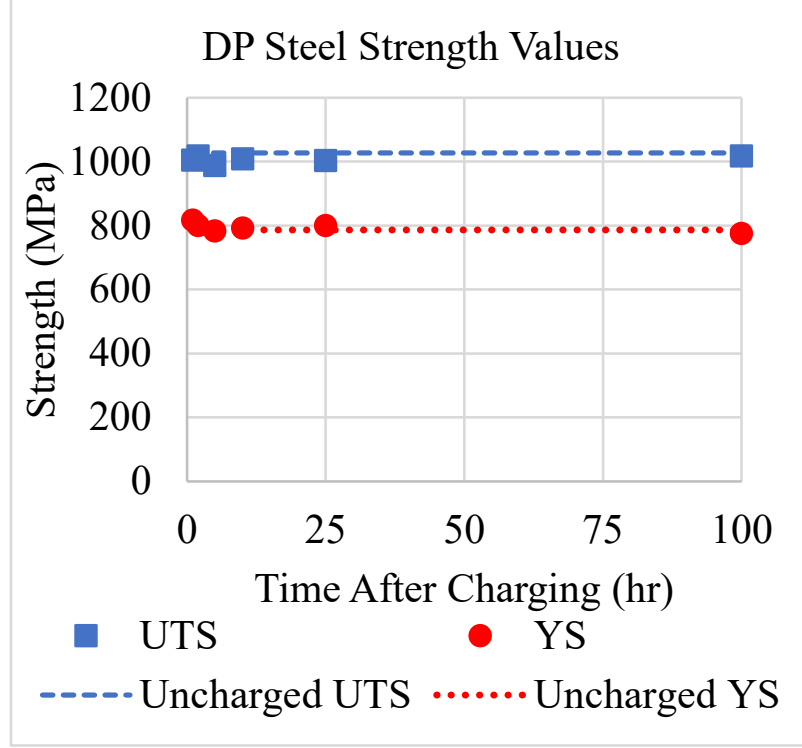

a

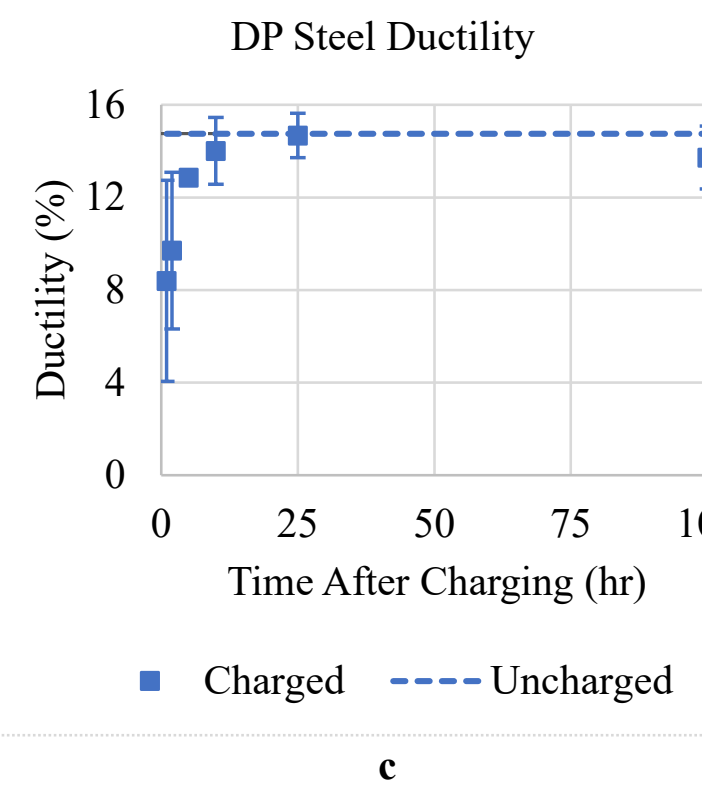

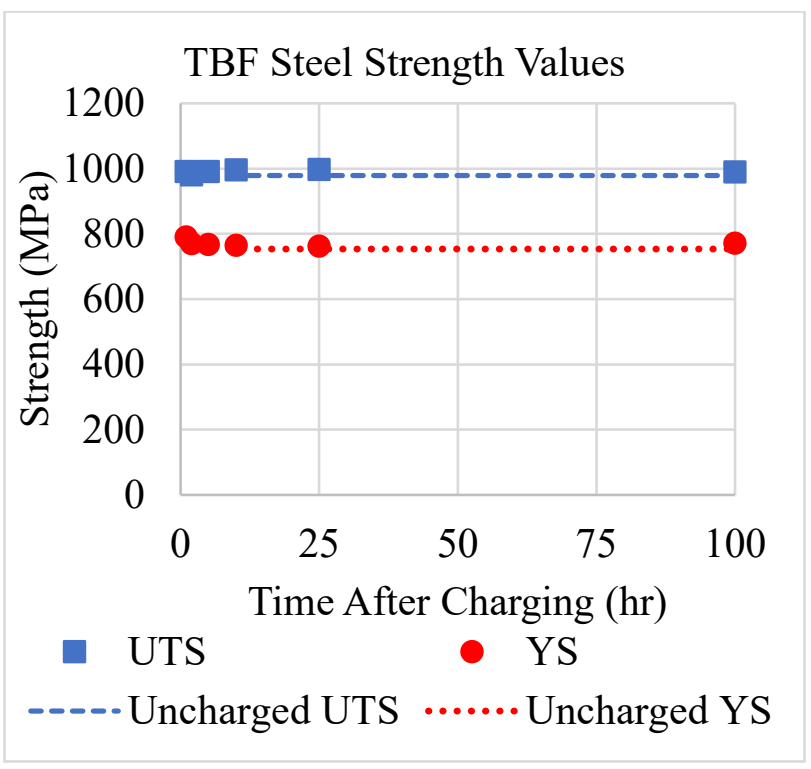

b

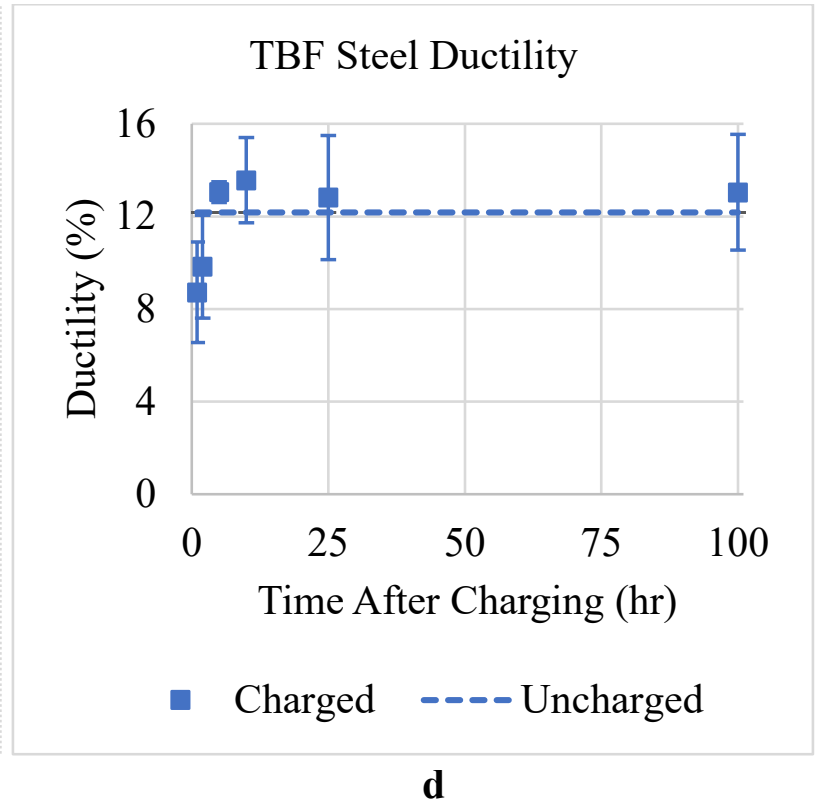

Figure 3-1: Results from the tensile tests. a) The ultimate tensile and yield strength of DP steel. b) UTS and YS of TBF steel. c) Ductility of DP steel. d) Ductility of TBF steel.

Best-fit equations for hydrogen concentration were calculated for both the DP steel:

$$
c=4.4 e^{-0.225 t}
$$


and the TBF steel:

$$
c=4.4 e^{-0.355 t}
$$

The leading coefficient represents the initial diffusible hydrogen concentration after charging, while the exponent is the decay rate. This decay rate is an important parameter in evaluating resistance and recovery from hydrogen over time, as it describes how quickly diffusible hydrogen can exit the steel matrix.

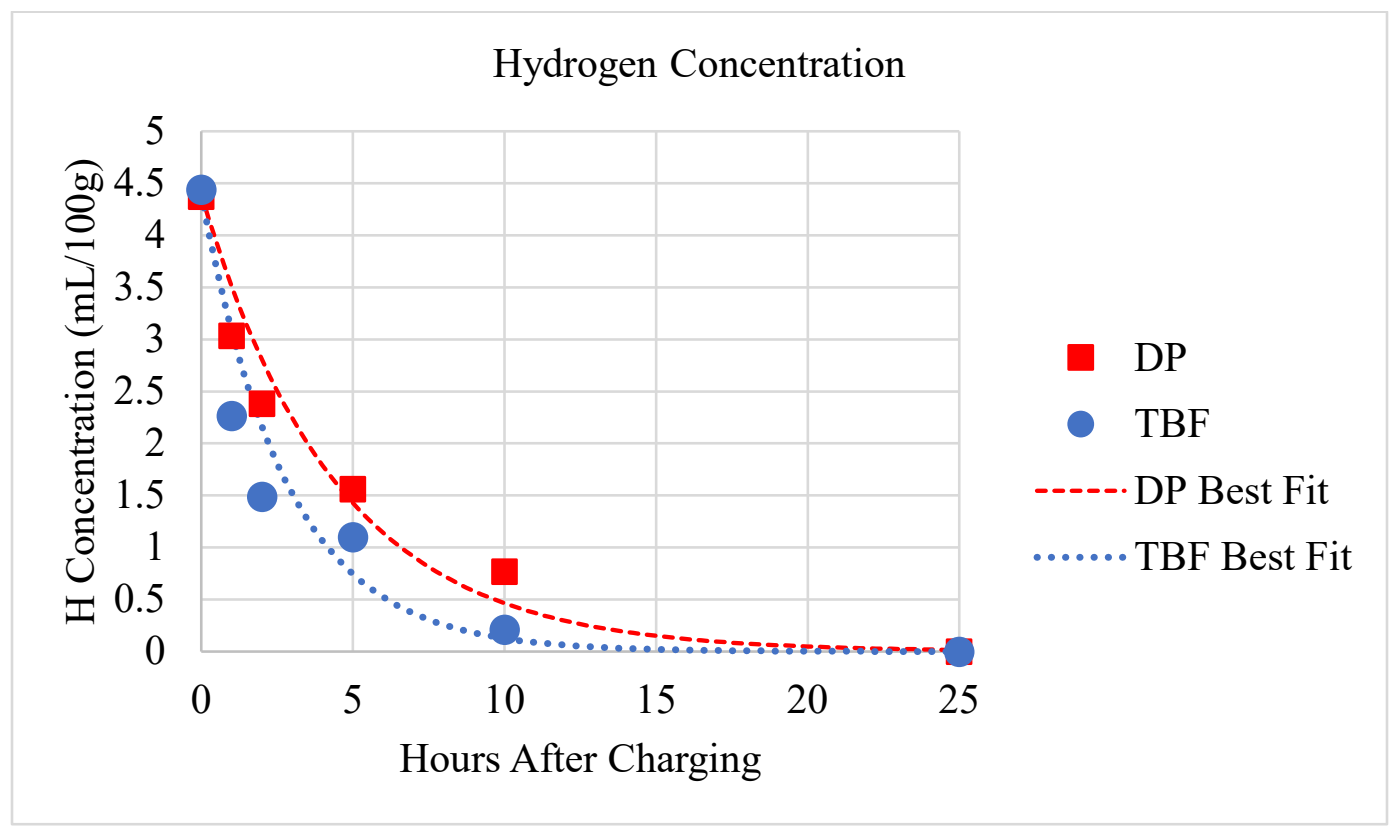

Figure 3-2: Diffusible hydrogen concentration of DP and TBF steel as a function of time post-charging. Best-fit equations are $4.4 e^{-0.225 t}$ for DP steel, and $4.4 e^{-0.355 t}$ for TBF.

\subsection{HMT / Microscopy}

Microprinting was used to identify hydrogen sinks and characterize diffusion rates of microstructures present on the steel sample surfaces. Figure 3-3 shows two microprint images of DP steel. Figure 3-3a was taken 1 hour after charging, and c was taken 5 hours after charging. 
Figure 3-3b and d show the EBSD IPF maps of those microprinted locations. In an IPF image, the crystalline orientation is illustrated with a unique color defined by the color-wheel in Figure 3-3e. The main orientations investigated in this study, namely the $<001>,<101>$ and $<111>$ directions, are depicted as red/orange, green, and blue/violet, respectively. Roman numerals in the figures pinpoint specific grains to list silver and hydrogen flux levels, as described in Section 2.5. Figure 3-4 shows microprints and IPF maps for TBF steel. The nearest orientation and silver decoration level for each numbered grain in the figures are compiled in Table 3-3 and Table 3-4.

Table 3-3: Orientation, silver-to-iron peak-height ratio (PHR), and the resulting representative flux data for numbered grains of DP steel in Figure 3-3.

\begin{tabular}{l|ccc}
\hline Grain \# & Nearest Orientation & Ag:Fe PHR & Representative Flux $\left(\mathrm{min}^{-1}\right)$ \\
\hline I & $<001>$ & 0.0492 & 0.00307 \\
II & $<101>$ & 0.0311 & 0.00207 \\
III & $<111>$ & 0.0133 & 0.00089 \\
IV & $<001>$ & 0.0092 & 0.00046 \\
V & $<101>$ & 0.0249 & 0.00124 \\
VI & $<111>$ & 0.0453 & 0.00227 \\
\hline
\end{tabular}

Table 3-4: Orientation, silver-to-iron peak-height ratio (PHR), and resulting representative flux data for numbered grains of TBF steel in Figure 3-4.

\begin{tabular}{l|ccc}
\hline Grain \# & Nearest Orientation & Ag:Fe PHR & Representative Flux $\left(\mathrm{min}^{-1}\right)$ \\
\hline I & $<001>$ & 0.0859 & 0.00859 \\
II & $<101>$ & 0.0880 & 0.00880 \\
III & $<111>$ & 0.0798 & 0.00798 \\
IV & $<001>$ & 0.0165 & 0.00824 \\
V & $<101>$ & 0.0386 & 0.00193 \\
VI & $<111>$ & 0.0708 & 0.00353 \\
\hline
\end{tabular}




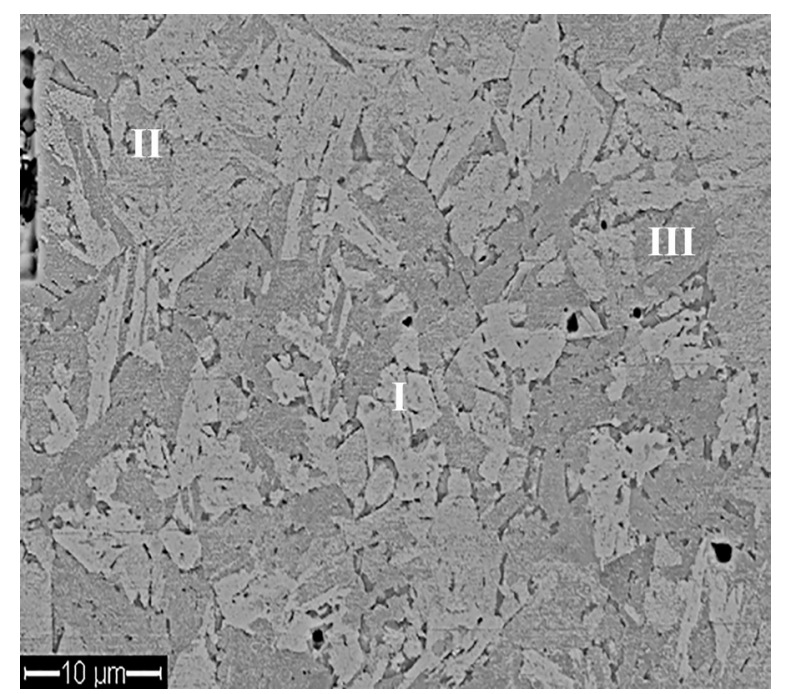

a

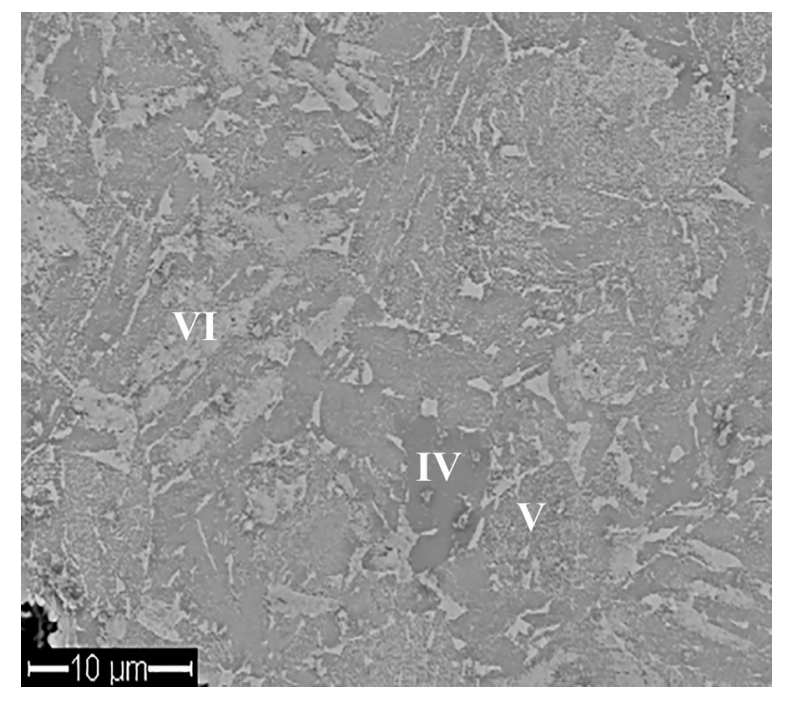

c

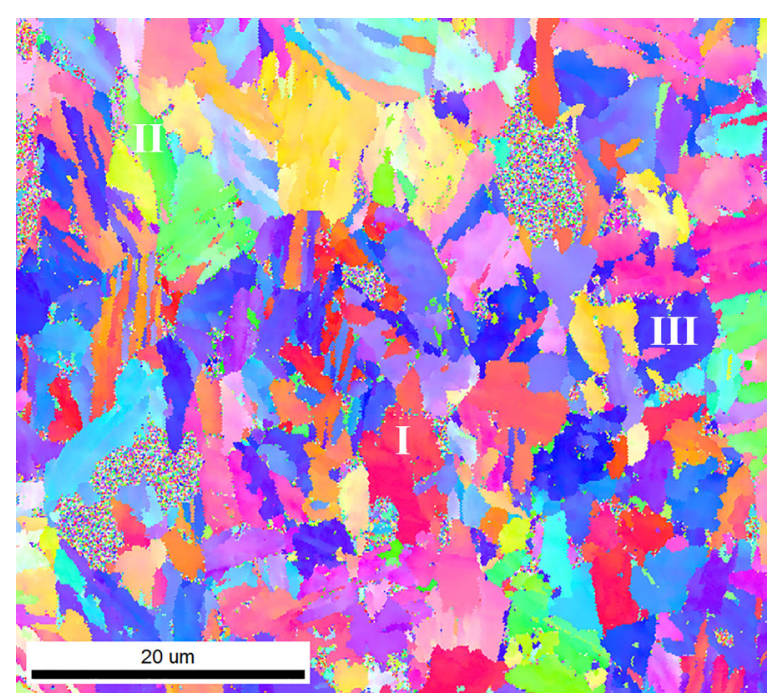

b

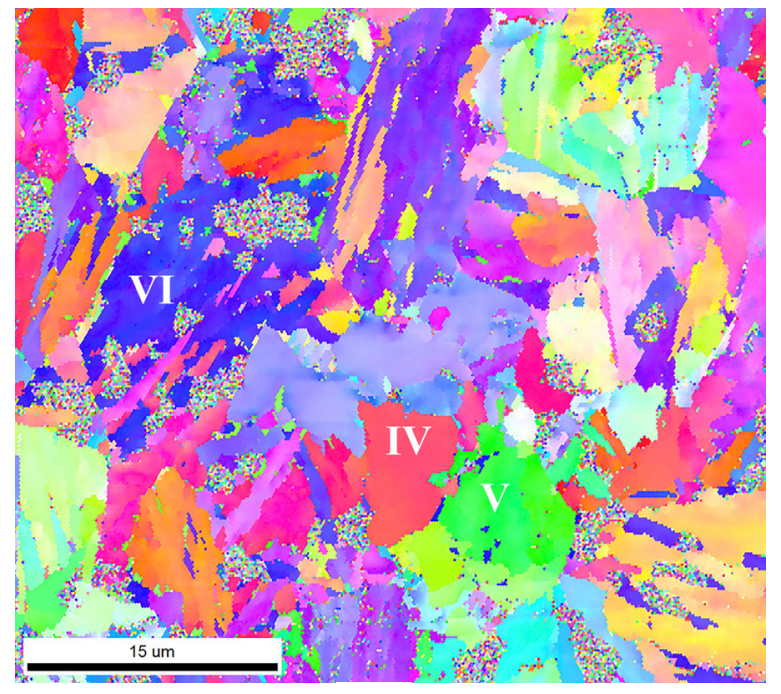

d

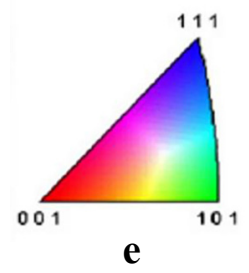

Figure 3-3: DP steel. a) BSE image of a microprint 1 hour post-charging (exposed 15 minutes), where silver shows up lighter. b) EBSD IPF map. c) BSE microprint image 5 hours after charging. d) Corresponding EBSD IPF map. e) 001 IPF color-wheel. Orientations and silver coverage data for numbered grains I-VI are compiled in Table 3-3. 


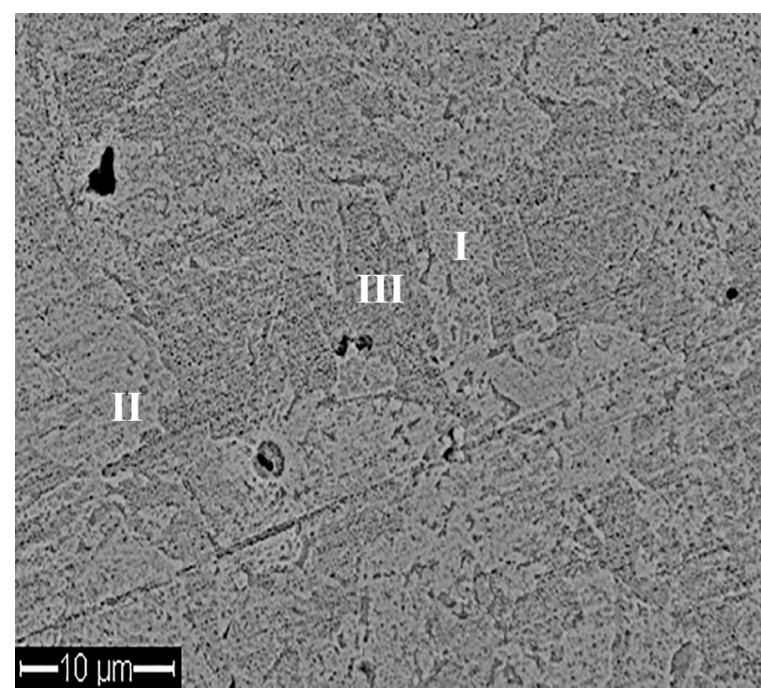

$\mathbf{a}$

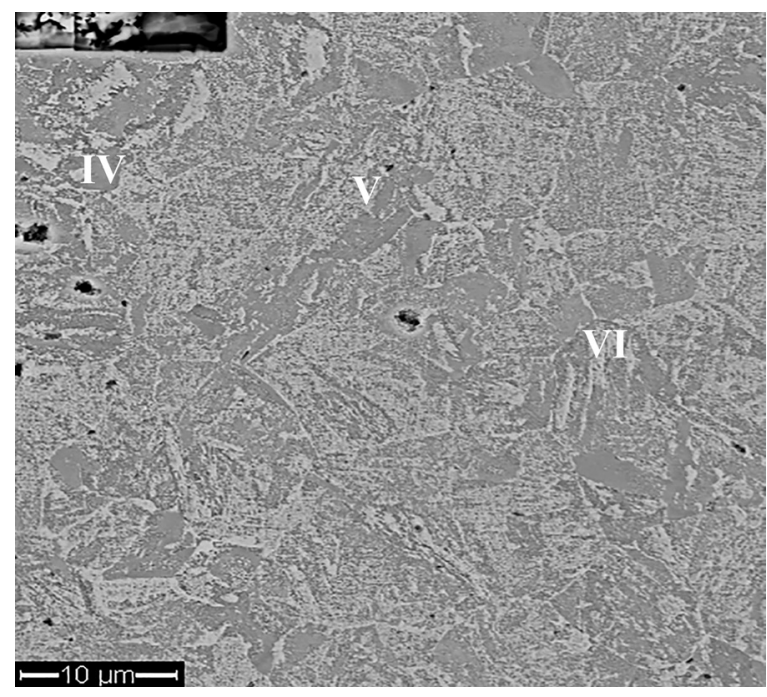

c

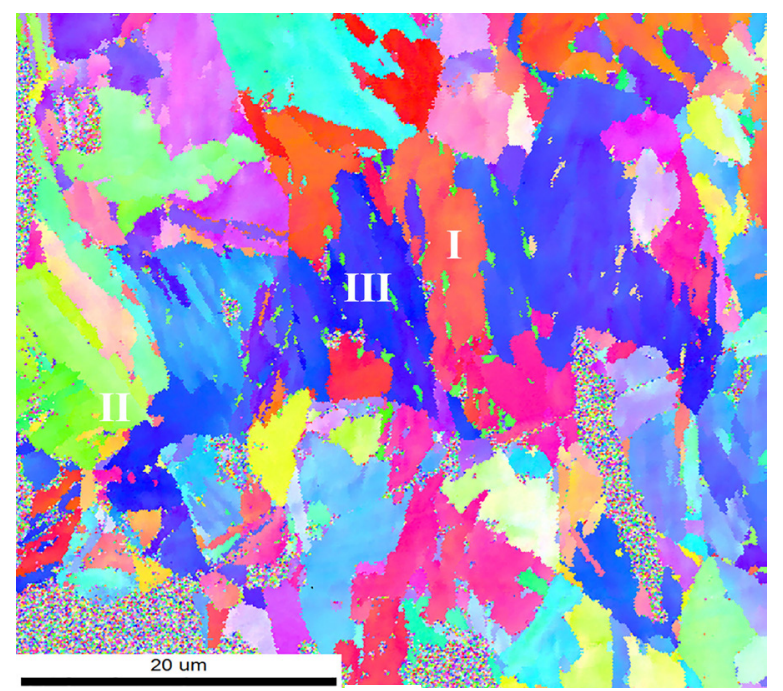

b

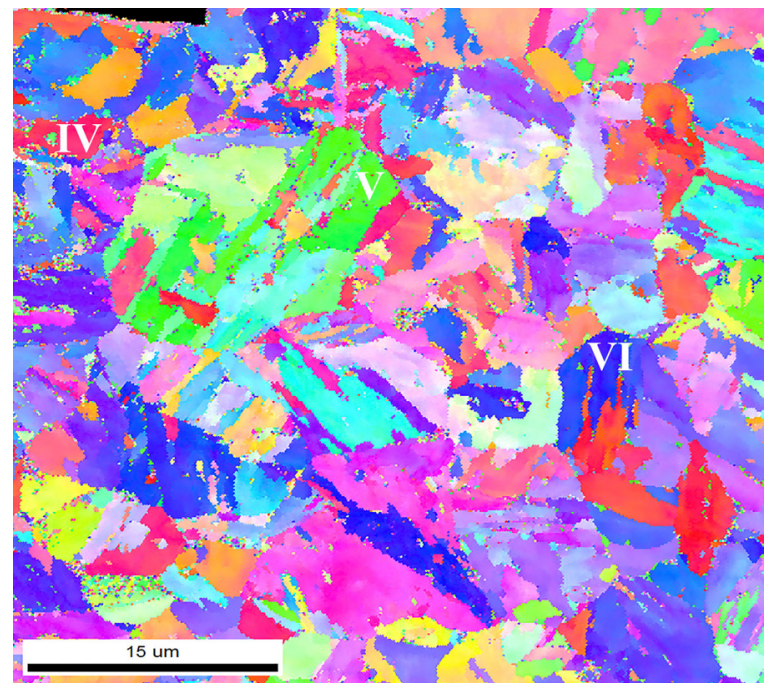

d

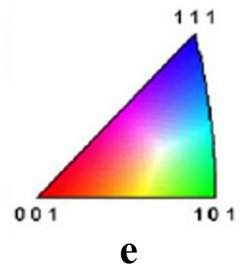

Figure 3-4: TBF steel. a) BSE image of microprint 1 hour after charging (10-minute exposure), and b) EBSD IPF map. c) BSE microprint 5 hours post charging. d) EBSD IPF map. e) 001 IPF color-wheel. The orientation and silver coverage values of the numbered grains are compiled in Table 3-4. 
The silver concentrations on various grains were quantified and converted to a representative hydrogen flux with the methods outlined in Section 2.5. Figure 3-5 shows this representative flux as a function of time for each type of steel. Observed hydrogen flux also follows an exponential decay over time. Best-fit equations of the form $y=A e^{B t}+C$ were calculated for the different orientations of each type of steel, where $t$ represents time after charging (in hours). The coefficient A represents an initial flux rate at the highest concentration level. The decay exponent, B represents the rate of decay, or how fast the flux rate drops. The value $\mathrm{C}$ is an equilibrium flux rate that the grain will eventually reach after time. This equilibrium flux is representative of the strength of a hydrogen trap, and is highest in grains of retained austenite. The values of A, B, and C for each steel type and orientation are compiled in Table 3-5.

Table 3-5: Coefficient values for hydrogen flux best-fit curves of the form $y=A e^{B t}+C$.

\begin{tabular}{l|ccc}
\hline Grain Orientation & $A$ & $B$ & $C$ \\
\hline DP $<001>$ & 0.0135 & -0.700 & 0.0015 \\
DP $<101>$ & 0.0080 & -0.450 & 0.0017 \\
DP $<111>$ & 0.0035 & -0.165 & 0.0015 \\
DP Martensite & 0.0085 & -0.315 & 0.0023 \\
\hline TBF $<001>$ & 0.0070 & -0.410 & 0.0010 \\
TBF $<101>$ & 0.0060 & -0.385 & 0.0012 \\
TBF $<111>$ & 0.0040 & -0.205 & 0.0012 \\
TBF Austenite & 0.0130 & -0.595 & 0.0040 \\
\hline
\end{tabular}




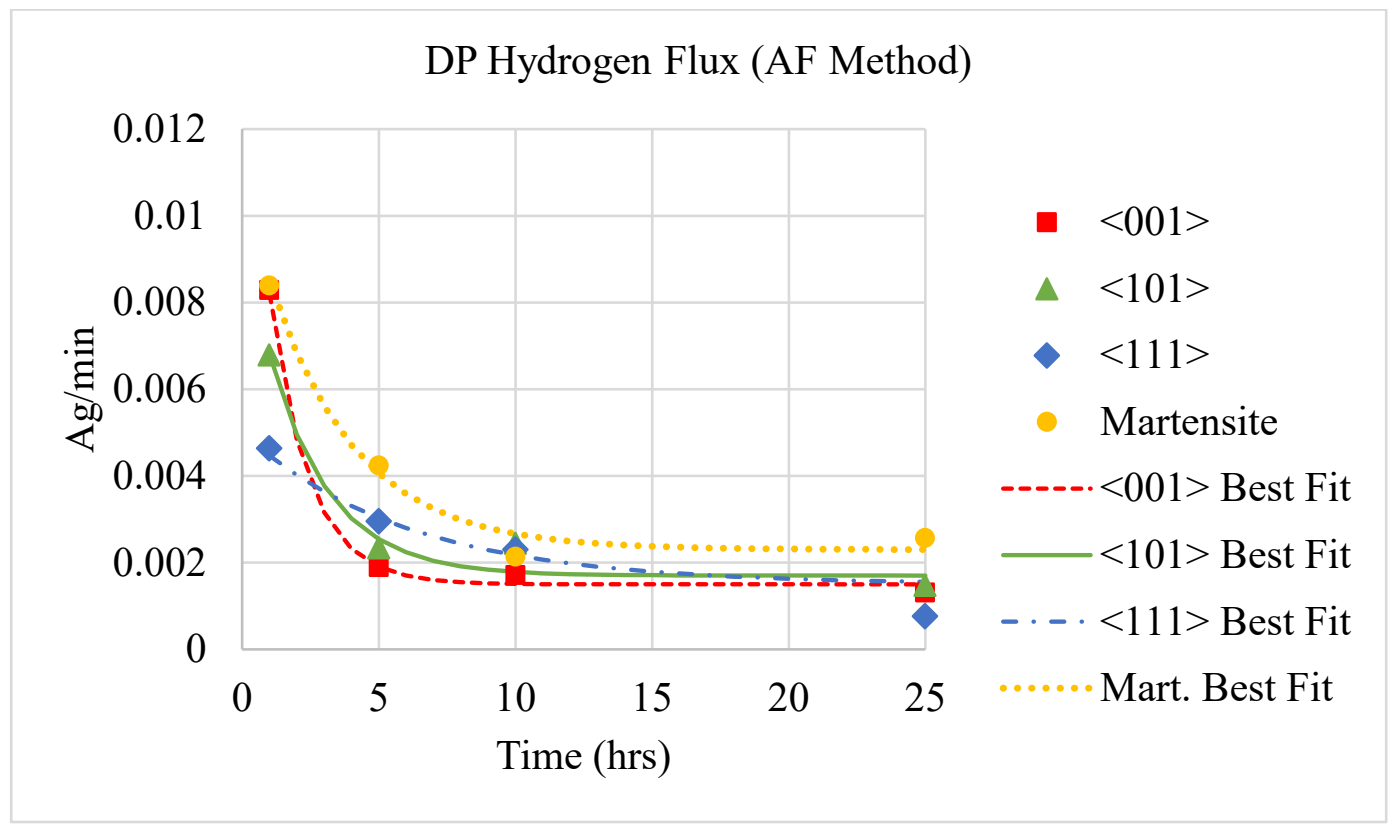

a

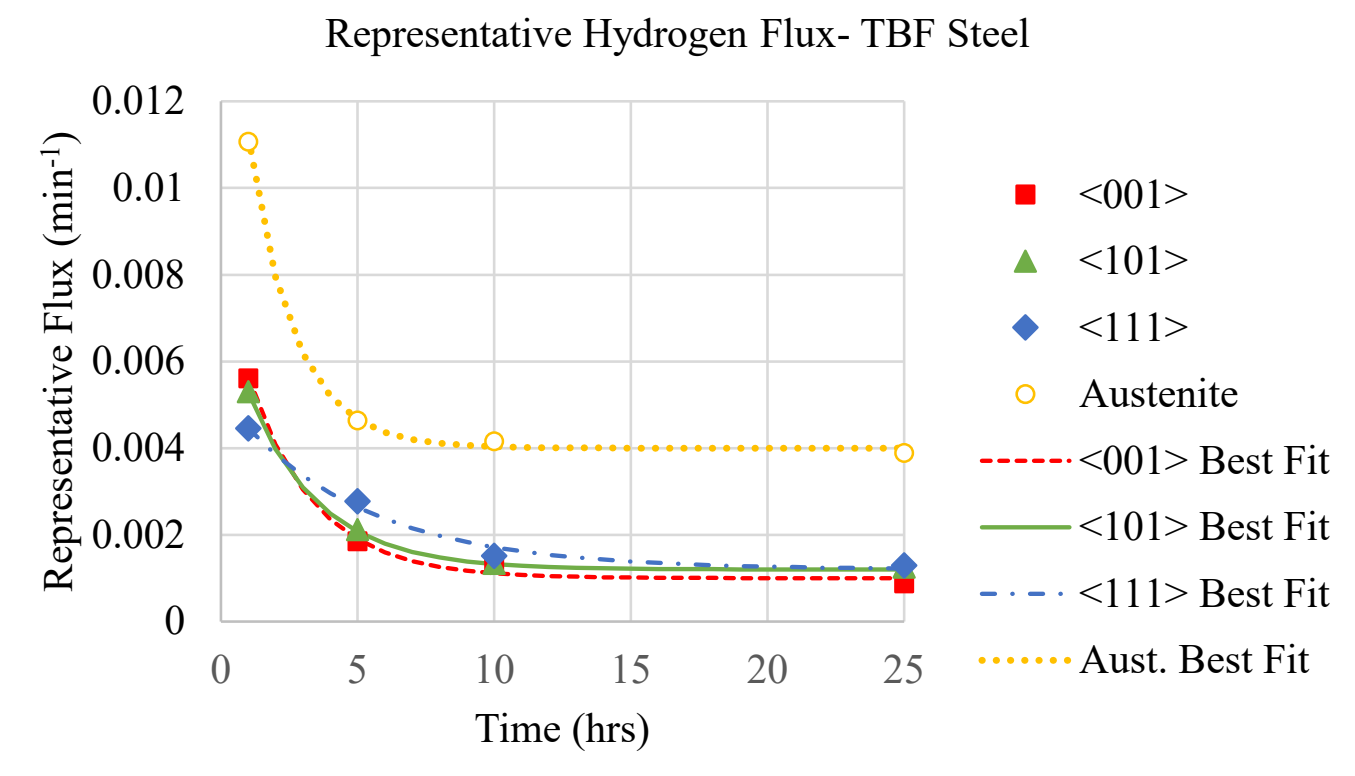

b

Figure 3-5: Representative hydrogen flux as a function of time for different orientations and phases. a) DP steel. b) TBF steel. 
In the steels investigated, $<001>$ orientations have the highest values of coefficient $\mathrm{A}$, meaning that they began with the highest level of hydrogen flux. $<001>$ grains also have the most negative values of $\mathrm{B}$, or the fastest decay rates, meaning they evolve hydrogen the fastest. $<101>$ grains also showed high levels of early flux and rapid decay rates. $<111>$ orientations began with lower flux levels, but retained hydrogen longer, due to slower decay over time. This phenomenon is apparent in Figure 3-3 and Figure 3-4, where microprints taken 1 hour after charging show $<001>$ and $<101>$ orientations decorated with more silver than $<111>$ orientations, indicating greater hydrogen flux. 5 hours after charging, however, $<111>$ grains show more silver than $<001>$ and $<101>$ grains. At 10 and 25 hours post-charging, differences between grains are small, and only trapping sites like austenite and martensite are significantly decorated with silver, i.e. are still evolving hydrogen. 


\section{DISCUSSION}

\subsection{Ductility as a Function of Hydrogen Concentrations}

The ductility of both DP and TBF steel were lowered by the presence of diffusible hydrogen in the matrix. Since tensile tests were conducted at the same time steps as concentration measurements, each level of measured ductility could be equated to a diffusible hydrogen concentration. Figure 4-1 shows the ductility of both steels as a function of hydrogen content, as well as best-fit curves and threshold limits of ductility and hydrogen concentration.

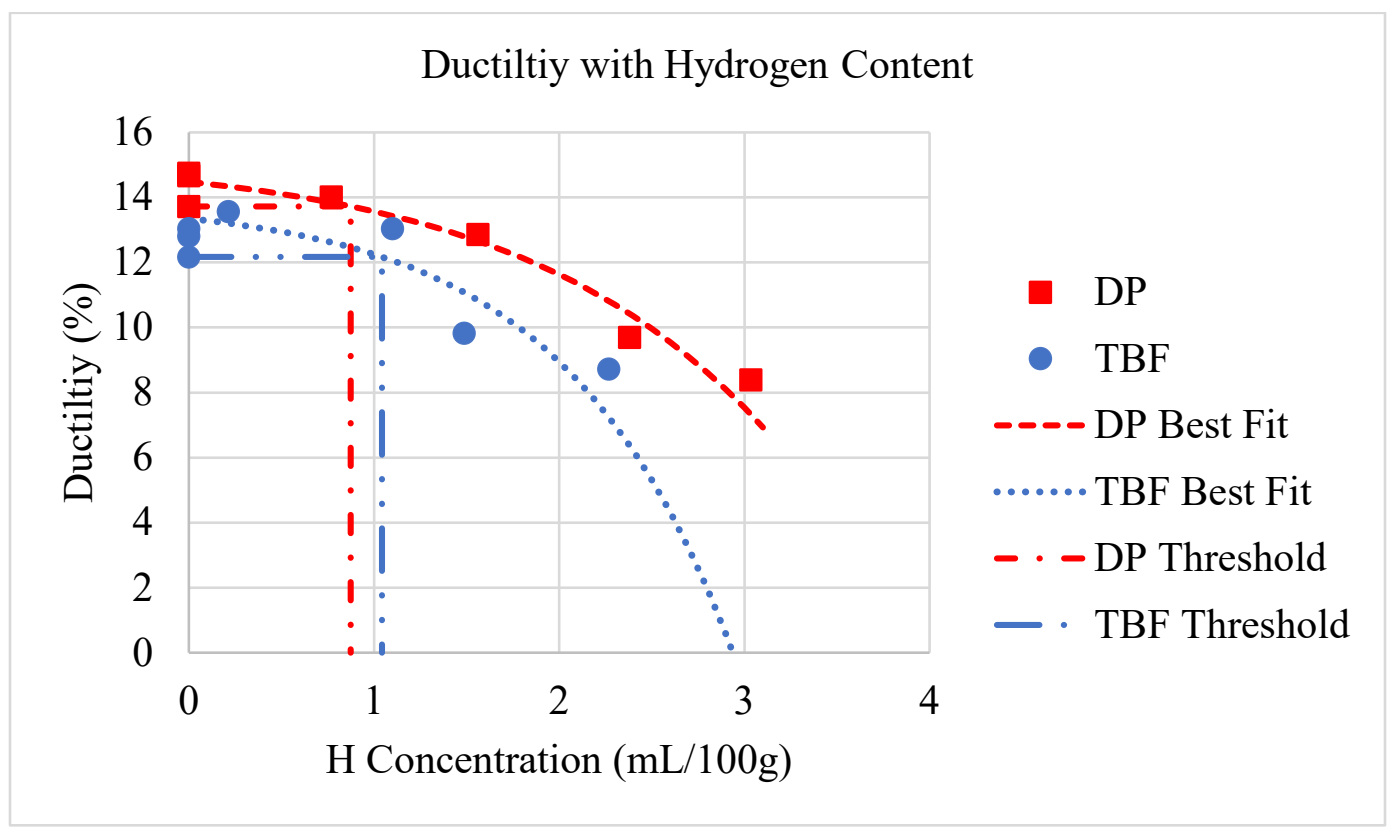

Figure 4-1: Ductility as a function of hydrogen concentration. The intercepts of the best-fit curves with the lowest measured ductility form hydrogen concentration threshold limits. 
Threshold hydrogen concentration levels were found by determining the intercept of the best-fit equations with the lowest level of ductility measured in the base metals. These threshold limits provide a conservative estimate of the range of hydrogen concentrations where the ductility of the steels remain in expected regions. Increasing the concentration beyond these limits runs the risk of decreasing the ductility. The threshold limits are found to be 0.87 and 1.04 $\mathrm{mL} / 100 \mathrm{~g}$ for DP and TBF steels, respectively.

Hydrogen was still observed in the steel after full recovery of ductility, though only at strong trapping sites such as martensite or austenite. Concentration measurements show that all diffusible hydrogen has left the steel within 25 hours after charging (see Figure 3-2). Figure 4-2a and $\mathrm{b}$ shows a microprinted sample of TBF steel 100 hours post-charging and the corresponding phase map from the EBSD scan. The austenite regions (shown as blue in Figure 4-2b) are decorated with silver (lighter regions of Figure 4-2a), showing that although the diffusible hydrogen concentration in the matrix is zero, trapped hydrogen still evolves from the austenite. Tensile tests showed that this amount of trapped hydrogen did not adversely affect ductility. Other experiments have also shown that trapped hydrogen does not affect ductility [7], [55].

A major contribution to the ductility of the TBF steel is the transformation of retained austenite into martensite. It has been proposed that hydrogen absorbed in austenite would be released in the transformation and cause the newly formed martensite to crack [1], [24]. The current experiments show that at 5 hours post-charging and beyond, tensile tests of TBF steel behave normally. Thus, the amount of hydrogen still trapped in the austenite packets clearly does not hinder the transformation or cause premature failure. More precise measurements will be 
needed to find the trapped hydrogen concentration limits that do affect phase transformation in austenite.

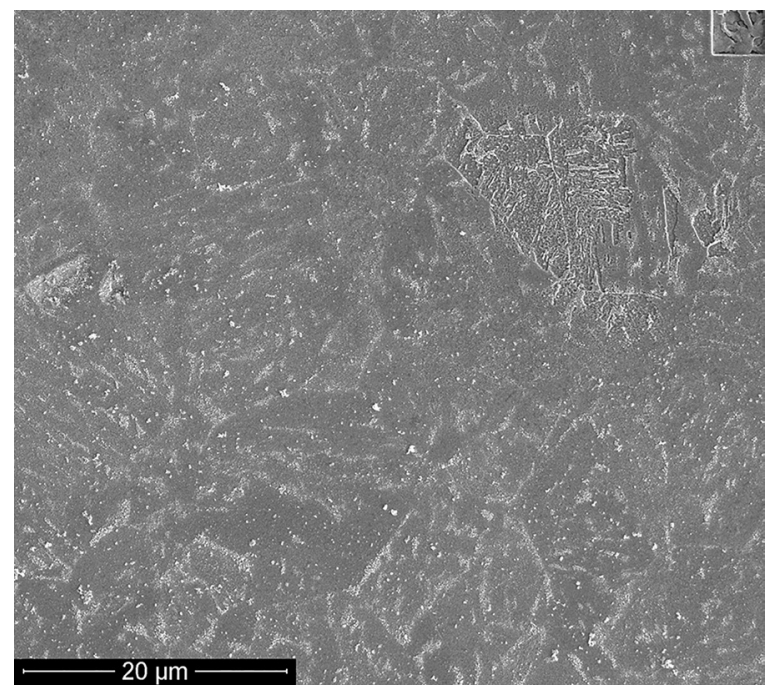

a

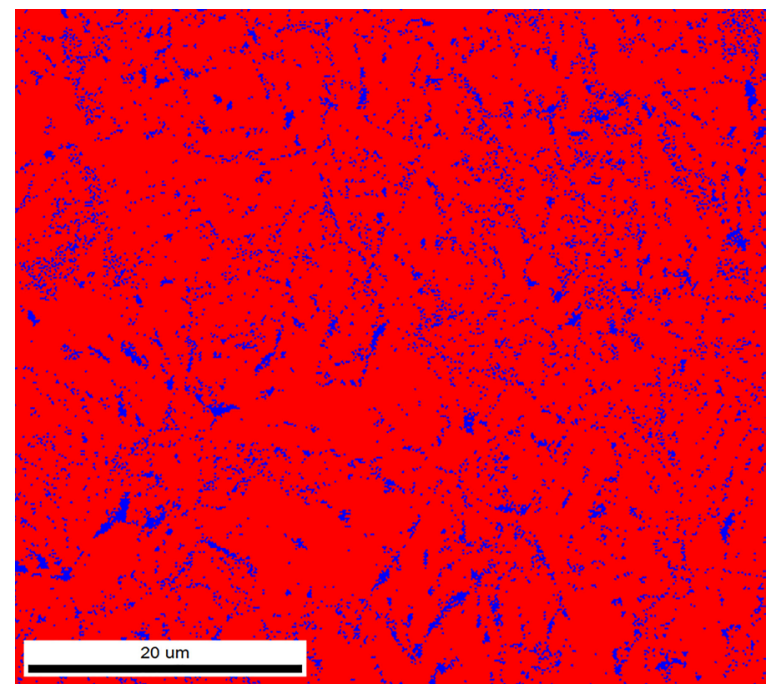

b

Figure 4-2: TBF steel 100 hours after charging shows hydrogen trapped in retained austenite. a) HMT image where silver is lighter. b) EBSD phase map, where blue represents austenite and red is ferrite.

\subsection{Anisotropic Orientation Dependence}

This study revealed that hydrogen diffusion shows preference to certain ferrite orientations over others in the early stages. The anisotropic trend observed here, where grains with the $<001>$ and $<101>$ orientations evolve hydrogen faster than $<111>$ orientations, has been shown previously in austenitic stainless steel [26]. The present study shows that initial flux from the $<001>$ and $<101>$ grains is respectively 1.7 and 1.4 times greater than $<111>$ grains in DP steel. Within 5 hours after charging, the $<001>$ and $<101>$ surface grains have emptied to the point that hydrogen flux out of the $<111>$ grains is now the highest. The fact that this anisotropy 
has been observed in multiple studies implies it is a real phenomenon, and not a byproduct of the microprinting.

One possible explanation for the observed anisotropic behavior could be surface effects. The present experiments can only observe diffusion at the surface layer. Bulk diffusion is generally an isotropic property. Hydrogen diffusion in steel proceeds along tetrahedral interstitial sites in BCC ferrite [56]. The symmetry of the cubic lattice allows interstitial diffusion in almost any direction. The surface energies of iron atom crystal lattice orientations are listed in Table 4-1. These values follow the trend that the $<111>$ orientation is different form the others. If a higher surface energy represents a higher energy barrier for hydrogen to exit the steel, then the slower initial flux rate of $<111>$ grains could be explained by surface energies of ferrite grain orientations.

Table 4-1: Surface energies of ferrite crystal orientations [57].

\begin{tabular}{l|c}
\hline Orientation & Surface Energy $\left(\mathrm{J} / \mathrm{m}^{2}\right)$ \\
\hline$<001>$ & 2.50 \\
$<101>$ & 2.45 \\
$<111>$ & 2.73 \\
\hline
\end{tabular}

\subsection{Resistance to Hydrogen Embrittlement}

A valuable measure for AHSS is their resistance to embrittlement when exposed to a hydrogen environment. A new, two-factor resistance index is proposed to help predict not only a material's performance at a given concentration, but to also show the time to recovery. A resistant microstructure will have a high threshold concentration value - requiring long exposure to hydrogen before absorbing deleterious levels — and dispel the hydrogen quickly when 
removed from the hydrogen environment. The combination of these two metrics, the threshold concentration and decay rate, can predict when a particular steel will be susceptible to embrittlement, and when that likelihood will be over.

In the present experiments, TBF steel showed greater resistance to embrittlement. TBF steel required a longer charging time than the DP steel and still recovered first. Immediately after charging, the two steels had similar concentrations of diffusible hydrogen in the matrix, but the decay rate of diffusible hydrogen in the TBF steel was greater than the DP steel. The threshold concentrations for the steels were calculated in Section 4.1 to be 0.87 and $1.04 \mathrm{~mL} / 100 \mathrm{~g}$ for DP and TBF steels, respectively. The decay exponents from Equations 3.1 and 3.2 are $-0.225 / \mathrm{hr}$ and $-0.355 / \mathrm{hr}$ for DP and TBF, respectively. From the combination of these values, TBF steel is more resistant to hydrogen due to its higher threshold concentration and faster decay rate. Figure 4-3 shows the recovery of the tested steels with a linear slope by plotting the natural logarithm of Equations 3.1 and 3.2. These equations predict that the diffusible hydrogen concentrations in the TBF and DP steels will fall below the thresholds after 4.1 and 7.2 hours, meaning that it takes almost twice as long for the DP steel to recover from the same initial concentration of diffusible hydrogen.

The increased hydrogen resistance in the TBF steel comes from the retained austenite in the microstructure. Thin laths of austenite between martensite laths have been shown to improve ductility of maraging TRIP steel in the presence of hydrogen [15]. Strong trapping sites like retained austenite slow down the overall hydrogen diffusion rate in steel. The slower diffusion limits the depth of hydrogen penetration during exposure, but could also prolong hydrogen escape after charging. A competing mechanism is that the traps may provide new escape routes 
for diffusion in the ferrite or martensite matrix. The TBF steel tested has small islands of retained austenite in the matrix and along grain boundaries. These abundant trap sites soak up hydrogen from surrounding grains, effectively shielding the ferrite from excessive hydrogen concentrations.

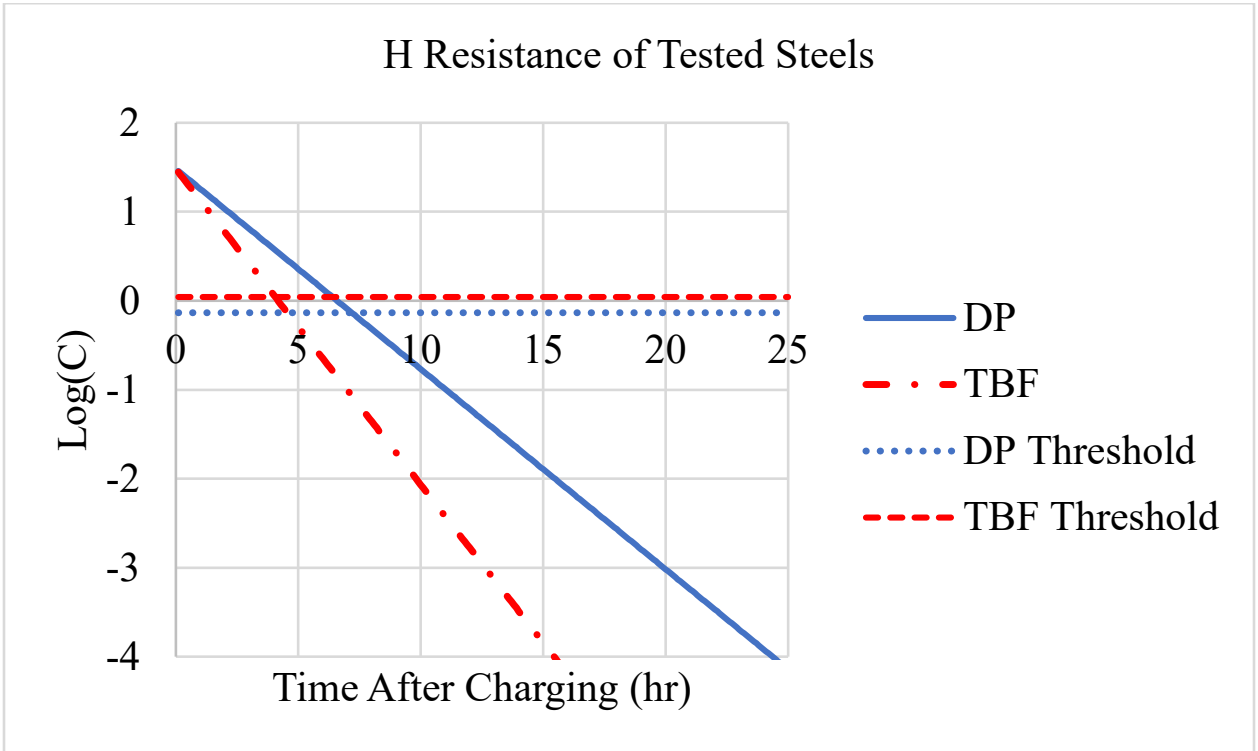

Figure 4-3: The hydrogen recovery of the tested steels. The charging brought both steels to a concentration of $4.4 \mathrm{~mL} / 100 \mathrm{~g}$. The hydrogen in TBF steel dissipates at a rate of $-0.355 / \mathrm{hr}$, and falls below the threshold concentration of $1.04 \mathrm{~mL} / 100 \mathrm{~g}$ after a time of 4.1 hours. The DP steel dissipates at a rate of $-0.225 / \mathrm{hr}$ to fall below $0.87 \mathrm{~mL} / 100 \mathrm{~g}$ after 7.2 hours.

Both the threshold and decay rate need to be considered. Current attempts to improve hydrogen resistance include maximizing the threshold limit for a given steel by introducing strong trapping sites, etc. [10], [18]. It is possible, however, that a faster decay rate will cause one type of steel to have superior resistance, even with a lower threshold tolerance. Figure 4-4 illustrates such a case. In this figure, two theoretical steels were charged to an initial hydrogen 
concentration of $4.5 \mathrm{~mL} / 100 \mathrm{~g}$. Steel 1 was given a threshold limit of $0.5 \mathrm{~mL} / 100 \mathrm{~g}$, compared to $1.5 \mathrm{~mL} / 100 \mathrm{~g}$ in steel 2 . The decay rates were given as $-0.50 / \mathrm{hr}$ for steel 1 and $-0.15 / \mathrm{hr}$ for steel 2. Despite the lower threshold limit, steel 1 recovered ductility in 4.4 hours, while steel 2 took 7.3 hours.

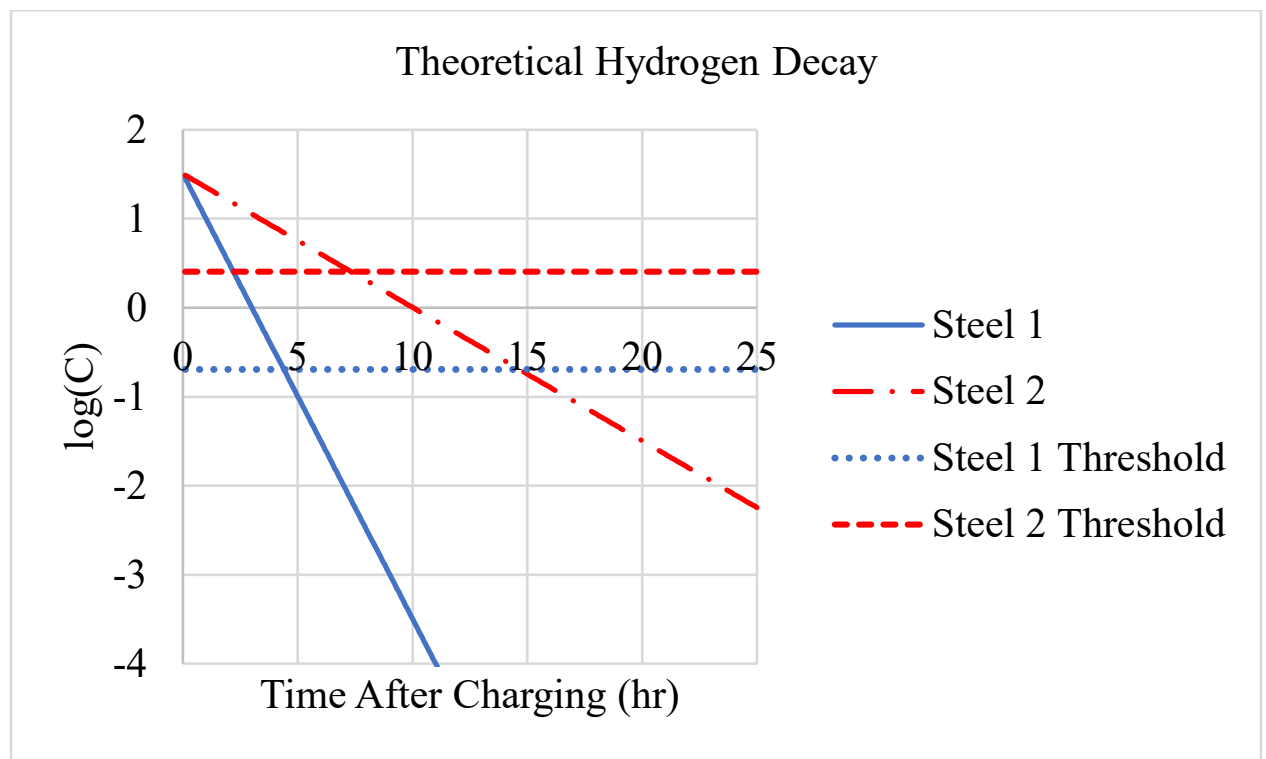

Figure 4-4: A theoretical hydrogen decay model to show how a steel with a lower hydrogen threshold can recover from charging faster, and thus be more resistant to $\mathrm{HE}$.

The new two-factor metric utilizes a logarithmic graph, as shown in Figure 4-3 and Figure 4-4. The log of the initial hydrogen content becomes the y-intercept, and the decay rate is the slope. The log of the threshold concentration is drawn as a horizontal line, and the point that the hydrogen concentration crosses the threshold represents the time of ductility recovery. Any hydrogen-steel system could be plotted this way, once an equation for the concentration over time and threshold hydrogen concentration are found. 
The thickness of the workpiece will affect the diffusion time. $1.6 \mathrm{~mm}$ thick sheet steels were tested here. Thicker pieces will require longer exposure times to reach equivalent levels of concentration, and take longer to diffuse out. Likewise, the threshold concentration for embrittlement of tensile tests may be different than that required for bending or punching tests. Multiple threshold lines can be drawn in each plot, and the one obtained from testing closest to the actual service loading of the steel can be used to determine recovery time. Assembling this data for other testing methods, steel types, and thicknesses will make this two-factor index a useful metric for the steel production line.

\subsection{Future Work}

As there are now multiple studies confirming the differences in surface diffusion speed for different crystallographic orientations, a logical next step is to establish an orientation dependent diffusion coefficient. It has been attempted here to quantify the differences of hydrogen flux, which will serve as a foundation for following studies to finish the quantification of hydrogen travel speed. The study of surface energy effects could also be investigated as a potential root cause for the observed anisotropy.

The methods presented in this paper could easily be applied to research other preferred pathways of hydrogen diffusion besides grain orientation. Other types of steel with different microstructures are prime candidates. Diffusion along geometrically necessary dislocations or grain boundaries, especially prior austenite grain boundaries, is of particular interest.

The new 2-factor metric to measure hydrogen resistance and recovery could be applied to a wider variety of steels. Knowledge of the time dependence of ductility recovery is useful to manufacturers. The dependence on thickness could be accounted for with a normalization to 
allow this method of viewing hydrogen recovery to be of greater practical importance. Expansion to include other types of steel as well as different geometries and testing methods will improve the impact of this metric. 


\section{CONCLUSIONS}

\subsection{DP Steel Response to Hydrogen}

DP steel was more affected by hydrogen than TBF. Ductility of DP steel decreases $43.1 \%$ at a hydrogen concentration of $3.1 \mathrm{~mL} / 100 \mathrm{~g}$ and recovers below a critical concentration of 0.87 $\mathrm{mL} / 100 \mathrm{~g}$. It takes 7.2 hours after hydrogen charging for the test specimens to diffuse enough hydrogen to be below the safe threshold hydrogen concentration. The decay rate of hydrogen in DP steel was found to be $-0.225 / \mathrm{hr}$.

\subsection{TBF Steel Response to Hydrogen}

Ductility of TBF steel decreases $28.3 \%$ at a hydrogen concentration of $2.3 \mathrm{~mL} / 100 \mathrm{~g}$ and recovers at a threshold of $1.04 \mathrm{~mL} / 100 \mathrm{~g}$. The TBF steel was exposed to the electrochemical hydrogen charging for 30 minutes longer than the DP steel to attain the same initial concentration, yet it recovered ductility within 4.1 hours after charging. With a higher threshold concentration, and a faster decay rate of $-0.355 / \mathrm{hr}$, TBF contains a more resistant microstructure to hydrogen embrittlement. The trapping behavior of the retained austenite enables this improved resistance. Retained austenite continues to trap and diffuse hydrogen after the ductility returns, indicating that the presence of equilibrium amounts of trapped hydrogen does not affect the martensitic transformation of austenite. 


\subsection{Anisotropic Hydrogen Diffusion}

Anisotropic hydrogen diffusion occurs in ferrite grains at high concentrations of diffusible hydrogen. 1 hour after charging, the $<001>$ and $<101>$ grains diffuse at least 1.2 times more hydrogen than $<111>$ grains in both DP and TBF steels. After 5 hours, however, diffusion in $<111>$ grains is greater, as the flux from the other orientations has dropped sharply. This trend has now been shown in multiple studies, and could be the result of a higher surface energy in the $<111>$ orientations.

\subsection{Hydrogen Embrittlement Recovery Index}

The decay rate of hydrogen concentration and critical hydrogen concentrations for embrittlement constitute the two factors in a new HE resistance index. Knowing these two values for a given steel species and thickness allows for the construction of a hydrogen concentration plot, and the prediction of when the material will recover from hydrogen exposure. These predictions will be of use in steel selection and manufacturing processes. 


\section{REFERENCES}

[1] G. Lovicu et al., "Hydrogen Embrittlement of Automotive Advanced High-Strength Steels," Metall. Mater. Trans. A, vol. 43, no. 11, pp. 4075-4087, 2012.

[2] T. Ruggles et al., "Ductility of Advanced High-Strength Steel in the Presence of a Sheared Edge," Jom, vol. 68, no. 7, pp. 1839-1849, 2016.

[3] M. Koyama, H. Springer, S. V. Merzlikin, K. Tsuzaki, E. Akiyama, and D. Raabe, "Hydrogen embrittlement associated with strain localization in a precipitation-hardened Fe-Mn-Al-C light weight austenitic steel," Int. J. Hydrogen Energy, vol. 39, no. 9, pp. 4634-4646, 2014.

[4] L. Vergani, C. Colombo, G. Gobbi, F. M. Bolzoni, and G. Fumagalli, "Hydrogen Effect on Fatigue Behavior of a Quenched \& Tempered Steel," Procedia Eng., vol. 74, pp. 468$471,2014$.

[5] X. Zhu, W. Li, H. Zhao, L. Wang, and X. Jin, "Hydrogen trapping sites and hydrogeninduced cracking in high strength quenching \& partitioning (Q\&P) treated steel," Int. J. Hydrogen Energy, vol. 39, no. 24, pp. 13031-13040, 2014.

[6] J. H. Ryu, S. K. Kim, C. S. Lee, D.-W. Suh, and H. K. D. H. Bhadeshia, "Effect of aluminium on hydrogen-induced fracture behaviour in austenitic Fe-Mn-C steel," Proc. R. Soc. A Math. Phys. Eng. Sci., vol. 469, no. 2149, pp. 20120458-20120458, 2012.

[7] T. Depover, D. Pérez Escobar, E. Wallaert, Z. Zermout, and K. Verbeken, "Effect of hydrogen charging on the mechanical properties of advanced high strength steels," Int. J. Hydrogen Energy, vol. 39, no. 9, pp. 4647-4656, 2014.

[8] T. Depover, E. Wallaert, and K. Verbeken, "Fractographic analysis of the role of hydrogen diffusion on the hydrogen embrittlement susceptibility of DP steel," Mater. Sci. Eng. A, vol. 649, pp. 201-208, 2016.

[9] M. A. Stopher, P. Lang, E. Kozeschnik, and P. E. J. Rivera-Diaz-del-Castillo, "Modelling hydrogen migration and trapping in steels," Mater. Des., vol. 106, pp. 205-215, 2016.

[10] A. Turnbull, "Perspectives on hydrogen uptake, diffusion and trapping," Int. J. Hydrogen Energy, vol. 40, no. 47, pp. 16961-16970, 2015. 
[11] M. A. Mohtadi-Bonab, J. A. Szpunar, and S. S. Razavi-Tousi, "A comparative study of hydrogen induced cracking behavior in API 5L X60 and X70 pipeline steels," Eng. Fail. Anal., vol. 33, pp. 163-175, 2013.

[12] M. Masoumi, H. L. F. Coelho, S. S. M. Tavares, C. C. Silva, and H. F. G. DeAbreu, "Effect of Grain Orientation and Boundary Distributions on Hydrogen-Induced Cracking in Low-Carbon-Content Steels," JOM, vol. 69, no. 8, pp. 1368-1374, 2017.

[13] A. Zinbi and A. Bouchou, "Delayed cracking in 301 austenitic steel after bending process: Martensitic transformation and hydrogen embrittlement analysis," Eng. Fail. Anal., vol. 17, no. 5, pp. 1028-1037, 2010.

[14] D. H. Shim, T. Lee, J. Lee, H. J. Lee, J.-Y. Yoo, and C. S. Lee, "Increased resistance to hydrogen embrittlement in high-strength steels composed of granular bainite," Mater. Sci. Eng. A, vol. 700, pp. 473-480, 2017.

[15] M. Wang, C. C. Tasan, M. Koyama, D. Ponge, and D. Raabe, "Enhancing Hydrogen Embrittlement Resistance of Lath Martensite by Introducing Nano-Films of Interlath Austenite," Metall. Mater. Trans. A Phys. Metall. Mater. Sci., vol. 46, no. 9, pp. 37973802, 2015.

[16] S. Takagi, Y. Hagihara, T. Hojo, W. Urushihara, and K. Kawasaki, "Comparison of Hydrogen Embrittlement Resistance of High Strength Steel Sheets Evaluated by Several Methods," ISIJ Int., vol. 56, no. 4, pp. 685-692, 2016.

[17] T. E. Garcia, C. Rodriguez, F. J. Belzunce, and I. I. Cuesta, "Effect of hydrogen embrittlement on the tensile properties of CrMoV steels by means of the small punch test," Mater. Sci. Eng. A, vol. 664, pp. 165-176, 2016.

[18] H. K. D. H. Bhadeshia, "Prevention of Hydrogen Embrittlement in Steels," ISIJ Int., vol. 56, no. 1, pp. 24-36, 2016.

[19] H. Lukito and Z. Szklarska-Smialowska, "Susceptibility of medium-strength steels to hydrogen-induced cracking," Corros. Sci., vol. 39, no. 12, pp. 2151-2169, 1997.

[20] Q. Liu, J. Venezuela, M. Zhang, Q. Zhou, and A. Atrens, "Hydrogen trapping in some advanced high strength steels," Corros. Sci., vol. 111, pp. 770-785, 2016.

[21] A. L. and D. . O. Y.D Park, I.S Maroef, "Retained Austenite as a Hydrogen Trap in Steel Welds," Weld. Res., pp. 27-35, 2002.

[22] Y. Mine, C. Narazaki, K. Murakami, S. Matsuoka, and Y. Murakami, "Hydrogen transport in solution-treated and pre-strained austenitic stainless steels and its role in hydrogenenhanced fatigue crack growth," Int. J. Hydrogen Energy, vol. 34, no. 2, pp. 1097-1107, 2009.

[23] T. Kanezaki, C. Narazaki, Y. Mine, S. Matsuoka, and Y. Murakami, "Effects of hydrogen 
on fatigue crack growth behavior of austenitic stainless steels," Int. J. Hydrogen Energy, vol. 33, no. 10, pp. 2604-2619, 2008.

[24] J. H. Ryu et al., "Effect of deformation on hydrogen trapping and effusion in TRIPassisted steel," Acta Mater., vol. 60, no. 10, pp. 4085-4092, 2012.

[25] H. K. Yalçì and D. V. Edmonds, "Application of the hydrogen microprint and the microautoradiography techniques to a duplex stainless steel," Mater. Charact., vol. 34, no. 2, pp. 97-104, 1995.

[26] Z. Hua, B. An, T. Iijima, C. Gu, and J. Zheng, "The finding of crystallographic orientation dependence of hydrogen diffusion in austenitic stainless steel by scanning Kelvin probe force microscopy," Scr. Mater., vol. 131, pp. 47-50, 2017.

[27] H. K. Birnbaum and P. Sofronis, "Hydrogen-enhanced localized plasticity-a mechanism for hydrogen-related fracture," Mater. Sci. Eng. A, vol. 176, no. 1-2, pp. 191-202, 1994.

[28] R. A. Oriani, "Hydrogen Embrittlement of Steels," Annu. Rev. Mater. Sci., vol. 8, pp. 327-357, 1978.

[29] M. Nagumo, T. Yagi, and H. Saitoh, "Deformation-induced defects controlling fracture toughness of steel revealed by tritium desorption behaviors," Acta Mater., vol. 48, no. 4, pp. 943-951, 2000.

[30] G. M. Pressouyre, "Current Solutions to Hydrogen Problems in Steel," in ASM, 1982, pp. $18-34$.

[31] O. Barrera, E. Tarleton, H. W. Tang, and A. C. F. Cocks, "Modelling the coupling between hydrogen diffusion and the mechanical behaviour of metals," Comput. Mater. Sci., vol. 122, pp. 219-228, 2016.

[32] M. B. Djukic et al., "Towards a unified and practical industrial model for prediction of hydrogen embrittlement and damage in steels," Struct. Integr. Procedia (Conference Fract. ECF21), vol. 2, p. 8, 2016.

[33] M. Koyama, C. C. Tasan, E. Akiyama, K. Tsuzaki, and D. Raabe, "Hydrogen-assisted decohesion and localized plasticity in dual-phase steel," Acta Mater., vol. 70, pp. 174187, 2014.

[34] M. Dadfarnia, P. Sofronis, and T. Neeraj, "Hydrogen interaction with multiple traps: Can it be used to mitigate embrittlement?," Int. J. Hydrogen Energy, vol. 36, no. 16, pp. 10141-10148, 2011.

[35] G. Gobbi, C. Colombo, S. Miccoli, and L. Vergani, "A numerical model to study the hydrogen embrittlement effect," Procedia Eng., vol. 74, pp. 460-463, 2014.

[36] F. D. Fischer, G. Mori, and J. Svoboda, "Modelling the influence of trapping on hydrogen 
permeation in metals," Corros. Sci., vol. 76, pp. 382-389, 2013.

[37] S. Jothi, T. N. Croft, L. Wright, A. Turnbull, and S. G. R. Brown, "Multi-phase modelling of intergranular hydrogen segregation/trapping for hydrogen embrittlement," Int. J. Hydrogen Energy, vol. 40, no. 43, pp. 15105-15123, 2015.

[38] A. McNabb and P. K. Foster, "A New Analysis of the Diffusion of Hydrogen in Iron and Ferritic Steels," Trans. Metall. Soc. AIME, vol. 227, pp. 618-627, 1963.

[39] R. A. Oriani, "The diffusion and trapping of hydrogen in steel," Acta Metall., vol. 18, 1970.

[40] A. Turnbull, M. W. Carroll, and D. H. Ferriss, "Analysis of hydrogen diffusion and trapping in a 13\% chromium martensitic stainless steel," Acta Metall., vol. 37, no. 7, pp. 2039-2046, 1989.

[41] T. Ohmisawa, S. Uchiyama, and M. Nagumo, "Detection of Hydrogen Trap Distribution in Steel Using a Microprint Technique," J. Alloys Compd., vol. 356-357, pp. 290-294, 2003.

[42] K. Ichitani, S. Kuramoto, and M. Kanno, "Quantitative evaluation of detection efficiency of the hydrogen microprint technique applied to steel," Corros. Sci., vol. 45, no. 6, pp. 1227-1241, 2003.

[43] M. A. V. Devanathan and Z. Stachurski, "The adsorption and diffusion of electrolytic hydrogen in palladium," in Proceedings of the Royal Society of London A: Mathematical and Physical Sciences, 1962, pp. 90-102.

[44] C. Senöz, S. Evers, M. Stratmann, and M. Rohwerder, "Scanning Kelvin Probe as a highly sensitive tool for detecting hydrogen permeation with high local resolution," Electrochem. commun., vol. 13, no. 12, pp. 1542-1545, 2011.

[45] T. E. Perez and J. Ovejero-Garcia, "Direct Observation of Hydrogen Evolution in the Electron Microscope Scale," Scr. Metall., vol. 16, pp. 161-164, 1982.

[46] J. Ovejero-Garcia, "Hydrogen microprint technique in the study of hydrogen in steels," $J$. Mater. Sci., vol. 20, pp. 2623-2629, 1985.

[47] J. a. Ronevich, J. G. Speer, G. Krauss, and D. K. Matlock, "Improvement of the Hydrogen Microprint Technique on AHSS Steels," Metallogr. Microstruct. Anal., vol. 1, no. 2, pp. 79-84, 2012.

[48] K. Ichitani and M. Kanno, "Visualization of Hydrogen Diffusion in Steels by High Sensitivity Hydrogen Microprint Technique," Sci. Technol. Adv. Mater., vol. 4, pp. 545$551,2003$.

[49] H. Matsunaga and H. Noda, "Visualization of Hydrogen Diffusion in a Hydrogen- 
Enhanced Fatigue Crack Growth in Type 304 Stainless Steel," Metall. Mater. Trans. A, vol. 42, no. 9, pp. 2696-2705, 2011.

[50] M. Koyama, D. Yamasaki, T. Nagashima, C. C. Tasan, and K. Tsuzaki, "In situ observations of silver-decoration evolution under hydrogen permeation: Effects of grain boundary misorientation on hydrogen flux in pure iron," Scr. Mater., vol. 129, pp. 48-51, 2017.

[51] B. L. Adams, "Orientation imaging microscopy: application to the measurement of grain boundary structure," Mater. Sci. Eng. A, vol. 166, no. 1-2, pp. 59-66, 1993.

[52] D. P. Field, "Recent advances in the application of orientation imaging," Ultramicroscopy, vol. 67 , no. 1-4, pp. 1-9, 1997.

[53] J. Rehrl, K. Mraczek, A. Pichler, and E. Werner, "Mechanical properties and fracture behavior of hydrogen charged AHSS/UHSS grades at high- and low strain rate tests," Mater. Sci. Eng. A, vol. 590, pp. 360-367, 2014.

[54] M. Hattori, H. Suzuki, Y. Seko, and K. Takai, "The Role of Hydrogen-Enhanced StrainInduced Lattice Defects on Hydrogen Embrittlement Susceptibility of X80 Pipeline Steel," JOM, vol. 69, no. 8, pp. 1375-1380, 2017.

[55] T. Doshida and K. Takai, "Dependence of hydrogen-induced lattice defects and hydrogen embrittlement of cold-drawn pearlitic steels on hydrogen trap state, temperature, strain rate and hydrogen content," Acta Mater., vol. 79, pp. 93-107, 2014.

[56] T. Hickel, R. Nazarov, E. J. McEniry, G. Leyson, B. Grabowski, and J. Neugebauer, “Ab Initio Based Understanding of the Segregation and Diffusion Mechanisms of Hydrogen in Steels," JOM, vol. 66, no. 8, pp. 1399-1405, 2014.

[57] R. Tran et al., "Surface energies of elemental crystals," Sci. Data, vol. 3, no. 160080, pp. 1-13, 2016. 


\section{APPENDIX A. HYROGEN MICROPRINT HANDBOOK}

\section{A.1 Introduction}

This handbook was written by Quentin Allen and Jon Mortensen to outline the important aspects of hydrogen microprinting. It gives instructions in enough detail such that ArcelorMittal (or any other interested researcher) can successfully recreate the work done at BYU, and build upon this foundation for more experiments in the future. References to other pertinent articles, a table of electrochemical hydrogen charging parameters used in literature, information on the chemicals used, and a quick reference guide to performing the experiment are included at the end.

\section{A.2 Background}

Hydrogen Microprint Technique (HMT) is a way of assessing local regions of hydrogen diffusion. In microprinting, a metal sample is charged with hydrogen, then covered with a thin photographic emulsion of silver bromide $(\mathrm{AgBr})$. As the hydrogen exits the sample surface, it reacts with the emulsion, leaving solid silver particles at the exit site. Figure A-1 illustrates the process. 

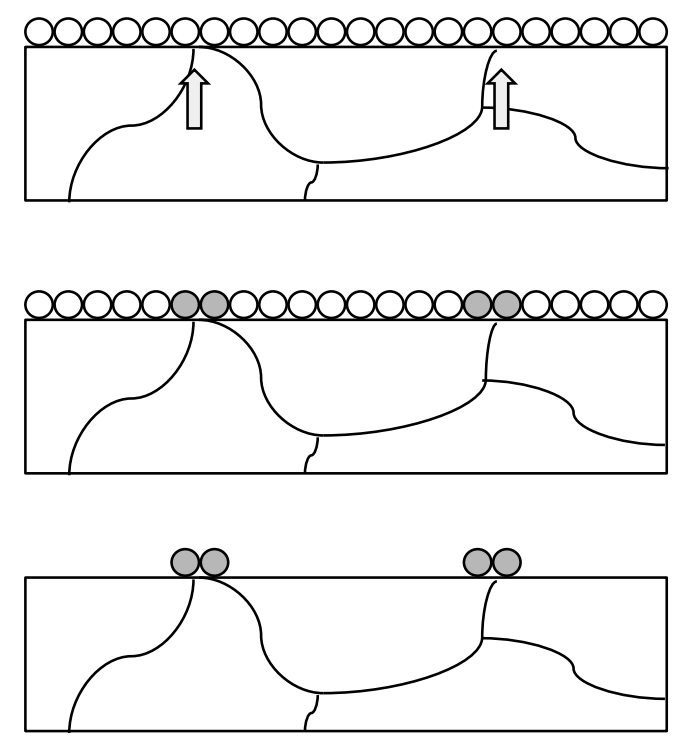

Figure A-1: Photographic emulsion coats the steel surface as hydrogen diffuses out. Silver ions at the exit locations are reduced by hydrogen. Undeveloped silver is washed away, leaving a map of hydrogen diffusion.

Figure A-2 shows what a microprinted sample looks like. The light grey regions are made up of silver particles, and the dark regions show the steel substrate where no particles developed. The silver particles observed here have a diameter of approximately 0.15 micrometers. Fine features smaller than 1 micron can be resolved by HMT. A successful microprint requires the steel sample to be adequately polished and charged with hydrogen, then the photographic emulsion must be applied, developed, and fixed before the microprint can be imaged. Each of these steps will be addressed in further detail in this document. 


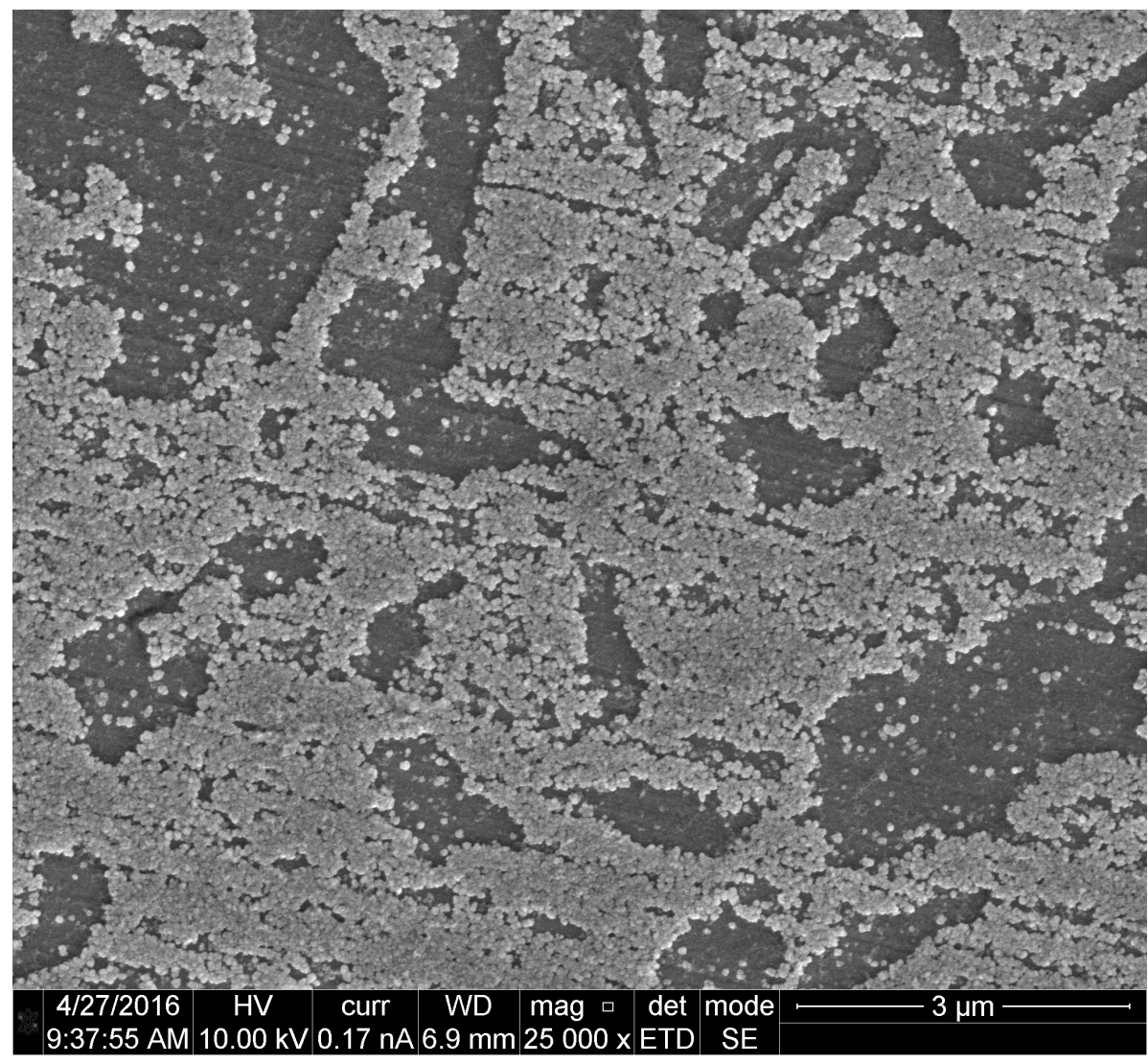

Figure A-2: A microprinted sample of TRIP steel. The picture was taken using an FEI Helios Nanolab 600 Scanning Electron Microscope (SEM) on BYU campus. It is at 25,000 $\mathrm{X}$ magnification and allows you to see individual silver grains. These grains were deposited where hydrogen left the sample.

\section{A.3 HMT Process}

\section{A.3.1 Sample Preparation}

Quality microprinting requires an excellent surface finish on the material to be examined.

Any roughness, such as scratches, pitting or etching, will leave air pockets against the surface, reducing the integrity of the microprint. The faint lines apparent in Figure A-2 illustrate how even fine polishing marks on the steel surface can show up in the final microprint. The 
experiments performed at BYU attempt to correlate HMT micrographs with Electron BackScatter Diffraction (EBSD) scans of the same area. Preparing samples for EBSD analysis also requires high quality polishing to achieve good results.

Best results were achieved by grinding and polishing the samples with the following order of abrasives. All grits of sandpaper were used for 1 minute each, followed by polishing with diamond paste for 10 minutes each. No set time was established for the alumina, as these were done by hand, but they averaged about 5 minutes of polishing time at each grit. After alumina polishing, samples were cleaned with ethanol in an ultrasonic cleaner, and polished with a water-free colloidal silica suspension for 2 hours on a vibratory polisher.

- 120 grit $\mathrm{SiC}$ paper

- 240 grit $\mathrm{SiC}$ paper

- 400 grit $\mathrm{SiC}$ paper

- 600 grit $\mathrm{SiC}$ paper

- 800 grit $\mathrm{SiC}$ paper

- 1200 coarse grit $\mathrm{SiC}$ paper

- 1200 fine grit $\mathrm{SiC}$ paper

- 6 micron diamond paste

- 3 micron diamond paste

- 1 micron diamond paste

- 1 micron colloidal alumina

- 0.3 micron colloidal alumina

- 0.05 micron colloidal silica (water-free) 
In the experiments performed at BYU, microprinting was completed before EBSD scans, and images compared to correlate hydrogen-rich regions with microstructure. As soon as samples were polished, they were charged with hydrogen and microprinted with the methods outlined below. A very short additional polishing step with 0.1 micron diamond paste was added after hydrogen charging and just before microprinting to ensure a smooth surface free from any adsorbed hydrogen. The samples were viewed in the SEM and interesting areas were marked with a Focused Ion Beam (FIB) to create fiducial marks. The microprints were cleaned off by soaking the samples in warm distilled water for 5 minutes, followed by 5 more minutes in the ultrasonic cleaner with soap water. This softened the microprint to the point that it could be removed gently with soap and a cotton ball. EBSD scans were then taken at the marked locations, and the images could be correlated.

\section{A.3.2 Hydrogen Charging}

Hydrogen charging was performed using an electrochemical method. Table A-1 lists charging times and solutions used by various experiments on different types of steel. At BYU, a 30V Protek power supply (model 3003L) was used to charge the samples with a current density of approximately $16.7 \mathrm{~mA} / \mathrm{cm}^{2}$ in a solution consisting of water, sulfuric acid, and the electrolyte thiourea. The sulfuric acid was purchased from Avantor Performance Chemicals, and is sold in concentrations of $95-98 \%$ acid (17.84-18.40 M). Pictures of the chemicals used at BYU are included later, and Table A-2 on the last page of the manual lists the amounts of each chemical used in the experiment. A corrosion-resistant stainless steel plate was used as the anode, as shown in Figure A-3. For TRIP steels, a longer charging time was necessary to produce sufficient concentration of hydrogen in the samples. After 2 hours of charging, the samples were 
lightly polished again for a few seconds with 0.1 micron diamond paste to remove any surface deposits left behind from hydrogen charging. Samples were allowed to sit for 1-2 hours after charging to allow the hydrogen to diffuse and accumulate in preferential microstructure locations that can be detected with the microprinting.

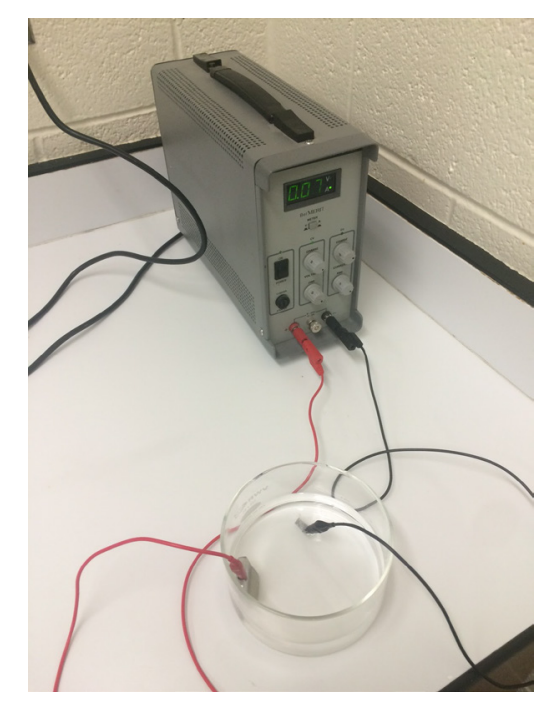

Figure A-3: The hydrogen charging set-up. Multiple samples can be charged at a time by adjusting the current accordingly.

\section{A.3.3 Emulsion Application}

The emulsion steps must be executed in a darkroom. Silver bromide is the active chemical used in black and white photography, and thus is sensitive to light. The $\mathrm{AgBr}$ emulsion used at BYU (Ag-Plus) was solid at room temperature and needed to be heated prior to use. The emulsion container was placed in warm water $\left(\sim 45^{\circ} \mathrm{C}\right)$ until the contents liquefied (see Figure A-4). The emulsion was prepared by mixing the liquefied $\mathrm{AgBr}$ with a solution of water and sodium nitrite. Concentrations are given in Table A-3. 
Most publications listed Ilford L4 as the silver bromide emulsion used. At BYU, we found that the Ag-Plus brand emulsion gave comparable results while being orders of magnitude less expensive. If using the Ilford L4 emulsion, the silver bromide can be added in its solid state, and the total solution can be gradually heated until liquefied. This method of heating the total emulsion also works to liquefy either brand of emulsion if it has sat at room temperature too long and hardened into a gel. The consistency of the emulsion before application to the sample should be a thick liquid.

A thin film of the liquid emulsion is applied to the surface of the sample using a wire loop, as shown in Figure A-5. The emulsion can be stirred with the loop until a film forms as the loop is removed. The loop should be just bigger than the size of the sample. The loop is lowered slowly over the sample so that an even film is deposited across the entire surface.

Once the emulsion is applied to the sample, the optimal time to let the emulsion develop is about 20 minutes. Water assists in the reduction of silver particles, so it is a good idea to control the ambient humidity in the darkroom to approximately $85 \%$. 


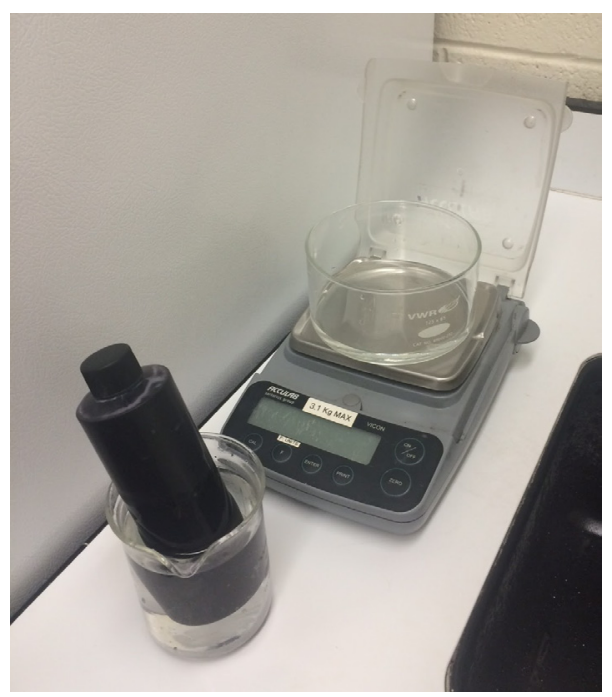

Figure A-4: The black bottle of AgBr photographic emulsion is resting in hot water. $10 \mathrm{~g}$ of the liquefied emulsion will be mixed into the container resting on the scale to make the final film solution.

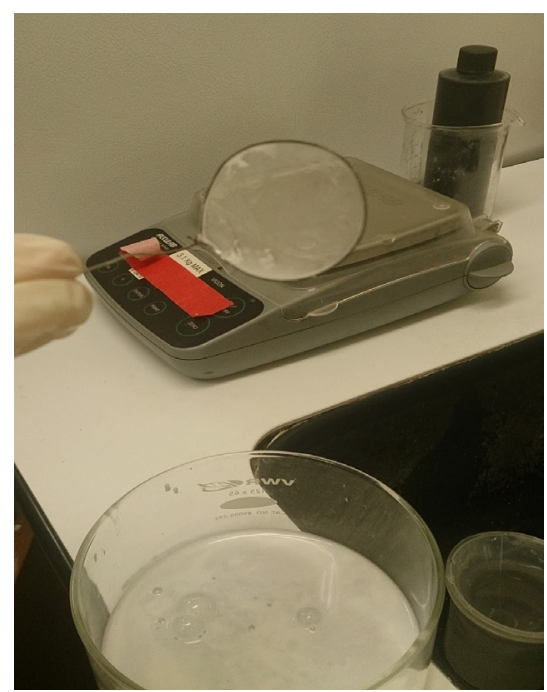

Figure A-5: The emulsion can be applied to the sample via a wire loop. This picture was taken after the process was completed; the lights should not be on. The white emulsion is starting to turn dark after just a few seconds of light exposure. 


\section{A.3.4 Emulsion Fixing}

Fixing is a photographic process that removes the unreacted silver bromide. The sample is dipped in formalin for 3 seconds to harden the film, and then placed into the fixing solution. This solution contains water, sodium thiosulfate, and sodium nitrite (see pictures and Table A-4). Fixing takes approximately 4 minutes with frequent, gentle agitation. The emulsion will turn clear in the fixing solution. The sample should be left in the solution at least twice the time it took to turn the emulsion clear, but leaving it in longer will not hurt the sample. The lights can be turned on after the fixing is completed.

Prompt cleaning of the sample after fixing is important to be able to later view the microprint in the SEM. Upon removal from the fixer, samples must be rinsed with distilled water so that the fixing chemicals do not crystallize on the sample. The gelatin from the emulsion must also be washed away with warm distilled water and a little soap, exposing the silver particles underneath. Placing the sample in an ultrasonic vibratory cleaner filled with warm distilled water for a few minutes, and then adding soap for another few minutes was found to work best. When the rinsing is done, the sample is rinsed with methanol and dried with a burst of compressed air so there is no water left on the steel to cause corrosion.

\section{A.3.5 Microprint Evaluation}

Microscopy techniques are required to assess the quality and perform analysis on the HMT. Optical microscopes can be used to see if microstructural features are visible, but the high magnification of an electron microscope is needed to resolve individual silver particles.

At low magnifications, it is difficult to tell whether the microprint was successful or not. Figure A-6 shows a view of a microprint at 2,500 X optical magnification. Figure A-7 shows this 
same sample at a higher magnification on the electron microscope. Figure A-8 and Figure A-9 show two other samples at high enough magnifications so that the individual silver grains are visible and illustrate the microstructure in the steel substrate.

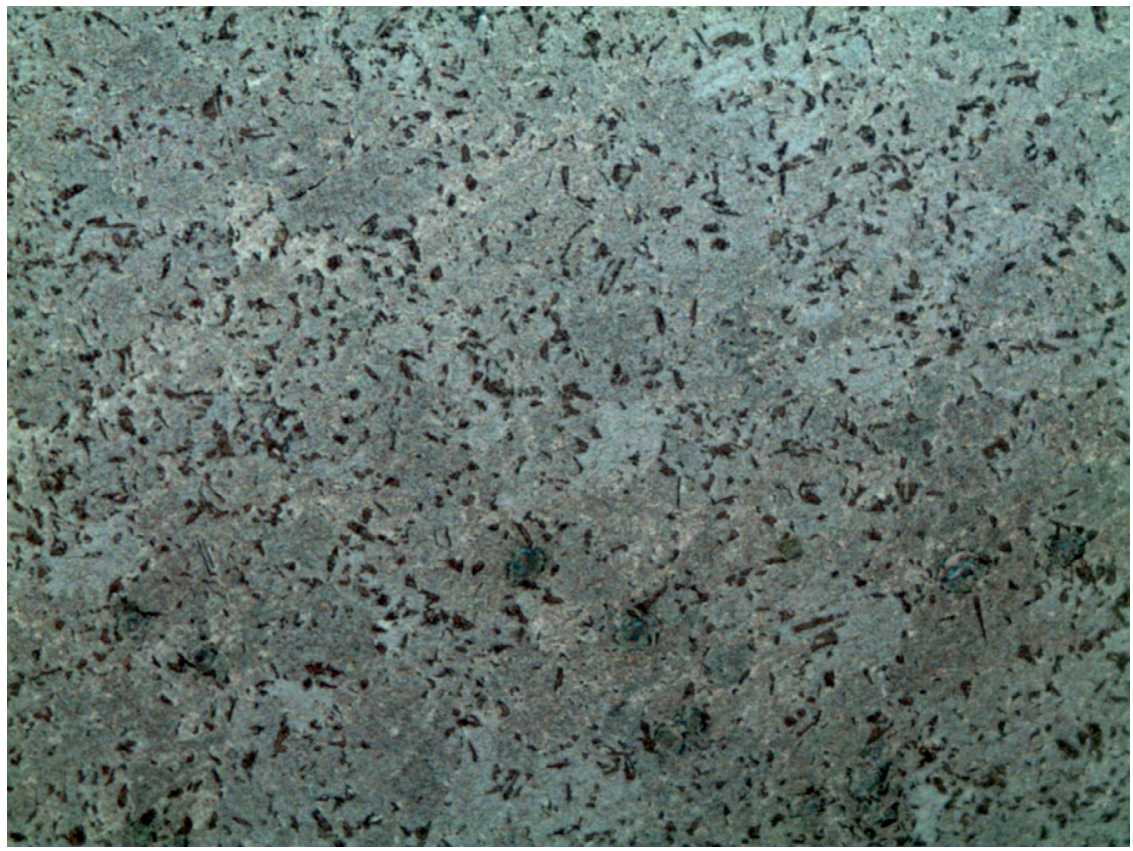

Figure A-6: This is a microprinted sample of TRIP steel under a light microscope at approximately 2,500 X magnification. Microstructural features are just visible, as there are some regions not covered with silver particles. 


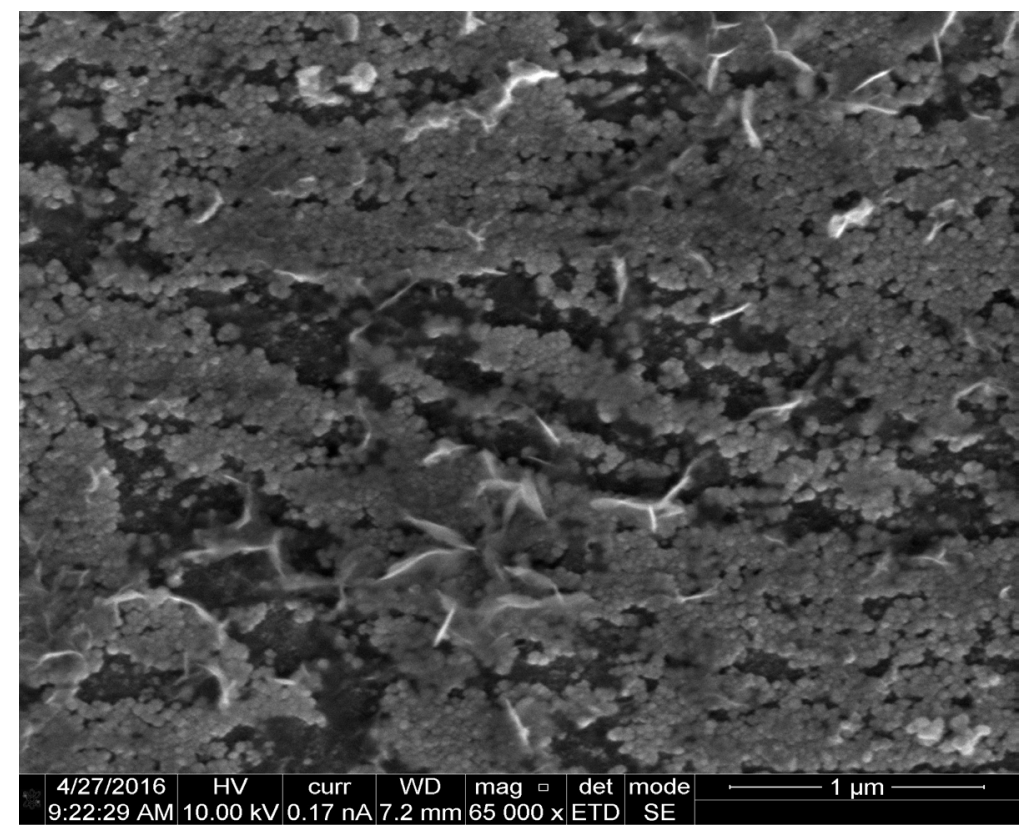

Figure A-7: This is the same sample as in Figure 6, but taken in the SEM at 65,000 X magnification. Silver particles are visible, along with a few 'flakes' that can make viewing the microprint difficult. Proper cleaning of the samples should reduce the amount of flakes.

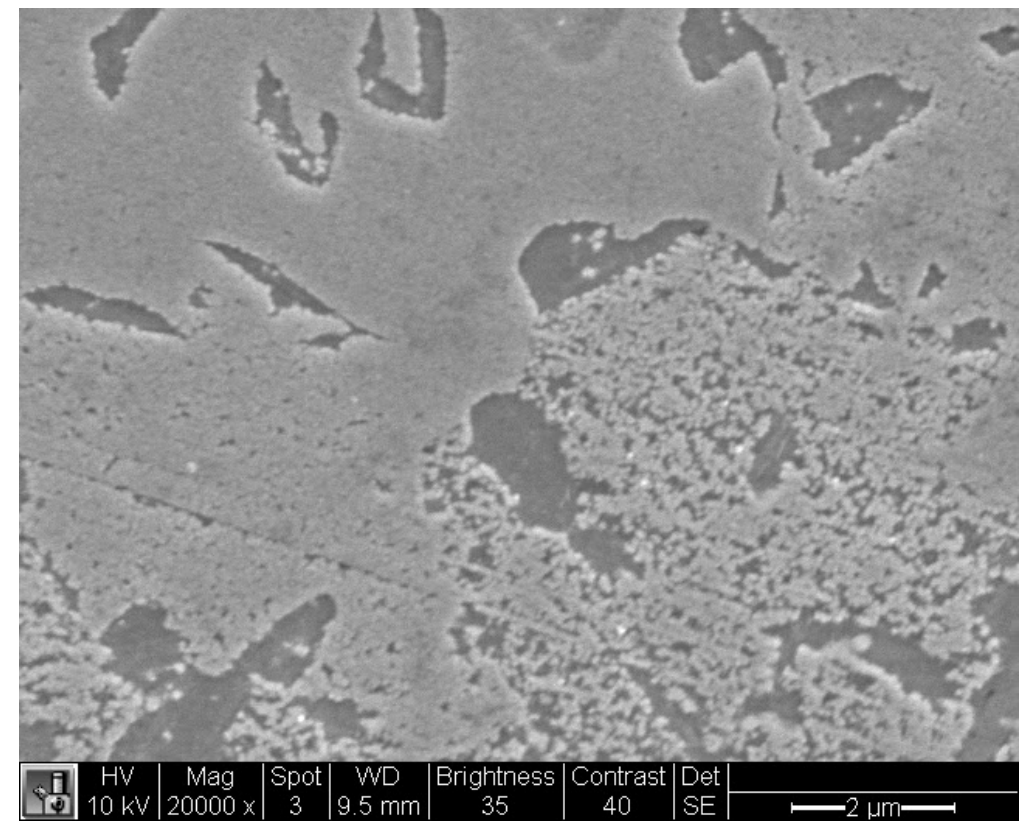

Figure A-8: This picture is another sample of microprinted TRIP steel at $20,000 \mathrm{X}$ magnification. This picture shows the fine resolution that can be achieved with microprinting. 


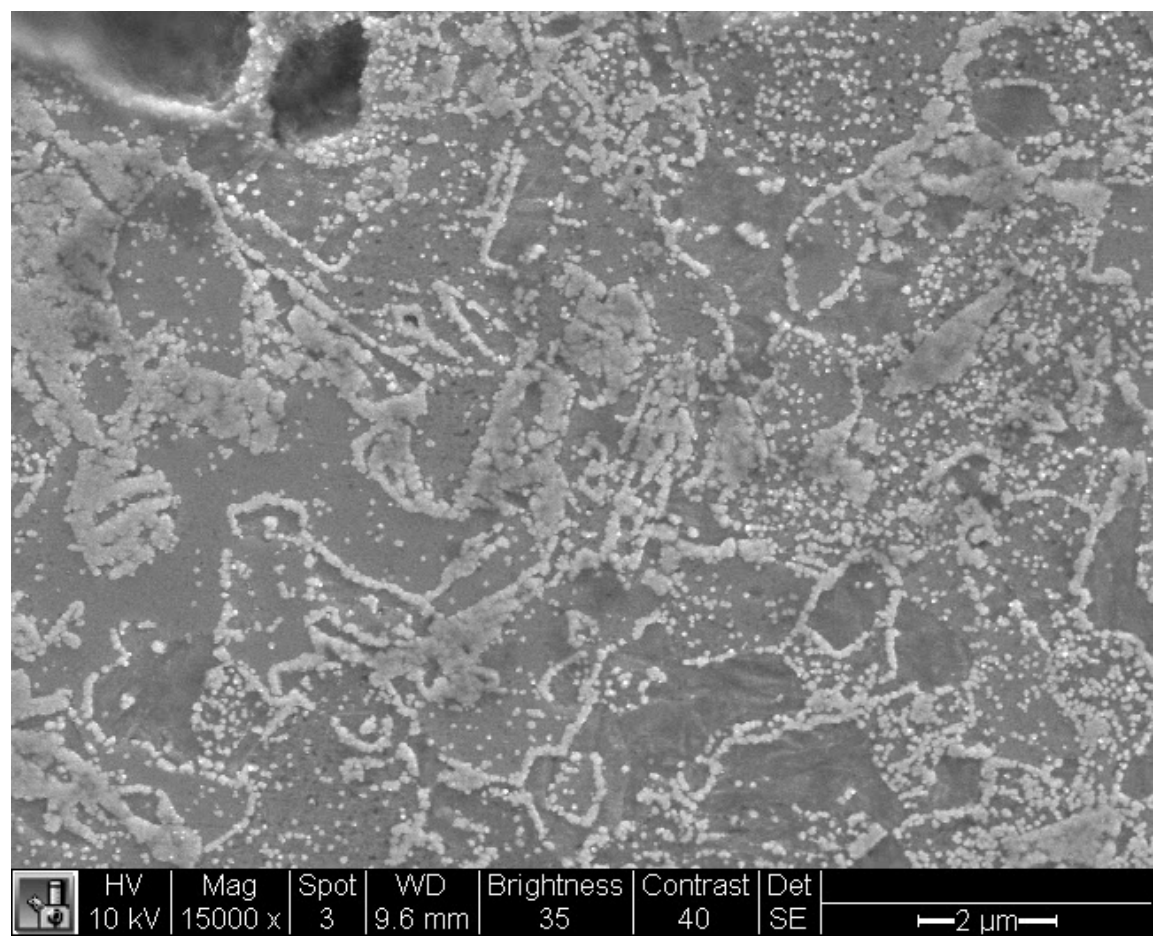

Figure A-9: This microprinted sample of TRIP steel at 15,000 X magnification shows more microstructural details, especially grain boundaries where hydrogen diffused out of the steel.

\section{A.3.6 Summary}

HMT is a useful tool for visualizing spatial locations of hydrogen entrapment in microstructural features. Tiny silver particles can be resolved, highlighting features smaller than 1 micron. The fine resolution comes as a result of the processes and procedures described above. The following sections summarize this information, and the last page is designed to be a quick guide in setting up the HMT experiment. Specific applications of these instructions will require adaptation. These processes were developed using Ag-Plus emulsion on DP-980 and TRIP steel samples in a size range of approximately $3 \times 1 \times 0.1 \mathrm{~cm}$. The times for charging, developing, and fixing may need to be altered to work for a different brand of emulsion, or a different sample material or size. 


\section{A.4 Scholarly Articles}

"Improvement of the Hydrogen Microprint Technique on AHSS Steels." J. A. Ronevich, J. G. Speer, G. Krauss, D. K. Matlock. Metallogr. Microstruct. Anal. (2012) Vol. 1.pg 79-84.

"Quantitative evaluation of detection efficiency of the hydrogen microprint technique applied to steel.” K. Ichitani, S. Kuramoto, M. Kanno. Corrosion Science. (2003) Vol. 45. pg 12271241.

"Visualization of hydrogen diffusion by high sensitivity HMT." K. Ichitani, and M. Kanno. Science and Technology of Advanced Materials. (2003) Vol. 4. pg 545-551.

“Application of the Hydrogen Microprint and the Microautoradiography Techniques to a Duplex Stainless Steel.” H. K. Yalci and D. V. Edmonds. Materials Characterization (1995) Vol. 34. pg 97-104.

"Direct Observation of Hydrogen Evolution in the Electron Microscope Scale." T. Perez, and J. Ovejero-Garcia. Scripta Metallurgica (1982) Vol. 16. pg 161-164.

\section{A.5 Hydrogen Charging Table}

This table is included to help guide decisions for electrochemical hydrogen charging, based on parameters listed in other experiments. 
Table A-1: Comparison of Hydrogen Charging Parameters.

\begin{tabular}{|c|c|c|c|c|}
\hline Author & Steel & $\begin{array}{l}\text { Charging } \\
\text { Current }\end{array}$ & Charging Time & Solution \\
\hline Koyama, 2014 & $D P$ & $0.2 \mathrm{~mA} / \mathrm{cm}^{2}$ & 1 hour & $\begin{array}{l}0.94 \mathrm{M} \mathrm{H}_{2} \mathrm{SO}_{4} \text { and } 3 \\
\mathrm{~g} / \mathrm{L} \mathrm{NH} \mathrm{SCN}_{4} \mathrm{SC}\end{array}$ \\
\hline Koyama, 2013 & TWIP & $0.9 \mathrm{~mA} / \mathrm{cm}^{2}$ & $\begin{array}{l}\text { During tensile } \\
\text { test with strain } \\
\text { rate: } 1.7 e-6 / \mathrm{sec}\end{array}$ & 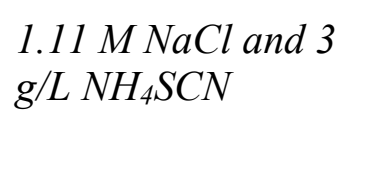 \\
\hline Perez, 1982 & $\begin{array}{l}316 L \\
\text { Stainless }\end{array}$ & $20 \mathrm{~mA} / \mathrm{cm}^{2}$ & 1 hour & $\begin{array}{l}0.5 \mathrm{M} \mathrm{H}_{2} \mathrm{SO}_{4} \text { and } 0.25 \\
\mathrm{~g} / \mathrm{L} \mathrm{As}_{2} \mathrm{O}_{3}\end{array}$ \\
\hline Depover, 2014 & $\begin{array}{l}D P, T R I P, \\
F B, H S L A\end{array}$ & $2.65 \mathrm{~mA} / \mathrm{cm}^{2}$ & 2 hours & $\begin{array}{l}0.5 \mathrm{M} \mathrm{H}_{2} \mathrm{SO}_{4} \text { and } 1 \\
\mathrm{~g} / \mathrm{L} \text { Thiourea }\end{array}$ \\
\hline Ryu, 2012 & TRIP & $\begin{array}{l}0.05-0.5 \\
\mathrm{~mA} / \mathrm{cm}^{2}\end{array}$ & 72 hours & $\begin{array}{l}1.11 \mathrm{M} \mathrm{NaCl} \text { and } 3.9 \\
\mathrm{~g} / \mathrm{L} \mathrm{NH} \mathrm{NHCN}_{4}\end{array}$ \\
\hline Kanezaki, 2008 & $\begin{array}{l}\text { Austenitic } \\
\text { Stainless }\end{array}$ & $2.7 \mathrm{~mA} / \mathrm{cm}^{2}$ & $\begin{array}{l}672 \text { hours, or } \\
336 \text { hours (pre- } \\
\text { strained) }\end{array}$ & $\mathrm{H}_{2} \mathrm{SO}_{4}(\mathrm{pH}$ of 3.5$)$ \\
\hline Narita, 1982 & $\begin{array}{l}304 \text { and } 310 \\
\text { Stainless }\end{array}$ & $\begin{array}{l}500-1000 \\
\mathrm{~mA} / \mathrm{cm}^{2}\end{array}$ & ?, At 293-373 K & $\begin{array}{l}0.5 \mathrm{M} \mathrm{H}_{2} \mathrm{SO}_{4} \text { and } \\
\mathrm{NaAsO}_{2}\end{array}$ \\
\hline $\begin{array}{l}\text { Mohtadi-Bonab, } \\
2013\end{array}$ & $\begin{array}{l}X 60 \text { and } \\
\text { X70 pipeline }\end{array}$ & $5 \mathrm{~mA} / \mathrm{cm}^{2}$ & $1 \mathrm{hr}$ & $\begin{array}{l}0.5 \mathrm{M} \mathrm{H}_{2} \mathrm{SO}_{4} \text { and } 3 \\
\mathrm{~g} / \mathrm{L} \mathrm{NH}_{4} \mathrm{SCN}\end{array}$ \\
\hline Yalci, 1995 & $\begin{array}{l}\text { Duplex } \\
\text { Stainless }\end{array}$ & $20 \mathrm{~mA} / \mathrm{cm}^{2}$ & $0.5-1 \mathrm{hr}$ & $\begin{array}{l}0.5 \mathrm{M} \mathrm{H}_{2} \mathrm{SO}_{4} \text { and } 0.25 \\
\mathrm{~g} / \mathrm{L} \mathrm{As}_{2} \mathrm{O}_{3}\end{array}$ \\
\hline Svoboda, 2014 & $\begin{array}{l}\text { Iron, CK60 } \\
\text { carbon steel }\end{array}$ & $10 \mathrm{~mA} / \mathrm{cm}^{2}$ & $?$ & $\begin{array}{l}0.1 \mathrm{M} \mathrm{NaOH} \text { and } 0.01 \\
\mathrm{~g} / \mathrm{L} \mathrm{As}_{2} \mathrm{O}_{3}\end{array}$ \\
\hline
\end{tabular}




\section{A.6 Chemicals Used in HMT}

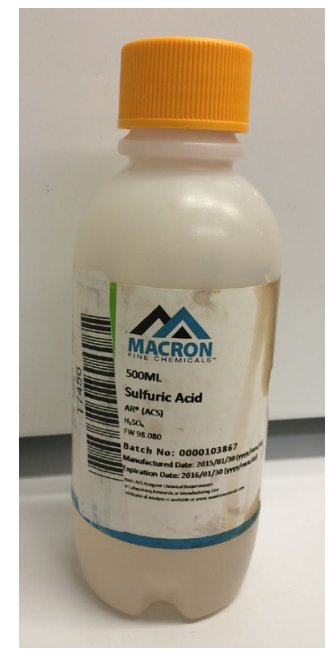

Sulfuric Acid: The hydrogen source for electrochemical hydrogen charging. The sulfuric acid used in hydrogen charging comes in high concentrations of 95-98\% acid, which corresponds to a molarity of $17.84-18.40$.

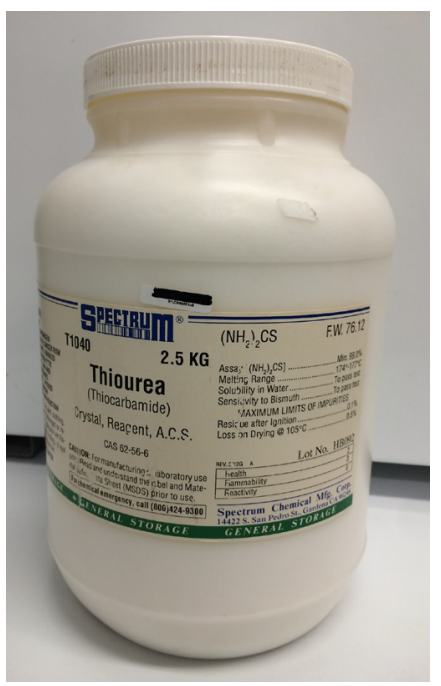

Thiourea: Thiourea is an electrolyte to help the flow of electricity and act as a hydrogen recombination poison in the hydrogen charging. The thiourea was cheapest in a large $2.5 \mathrm{~kg}$ bottle of powder. 


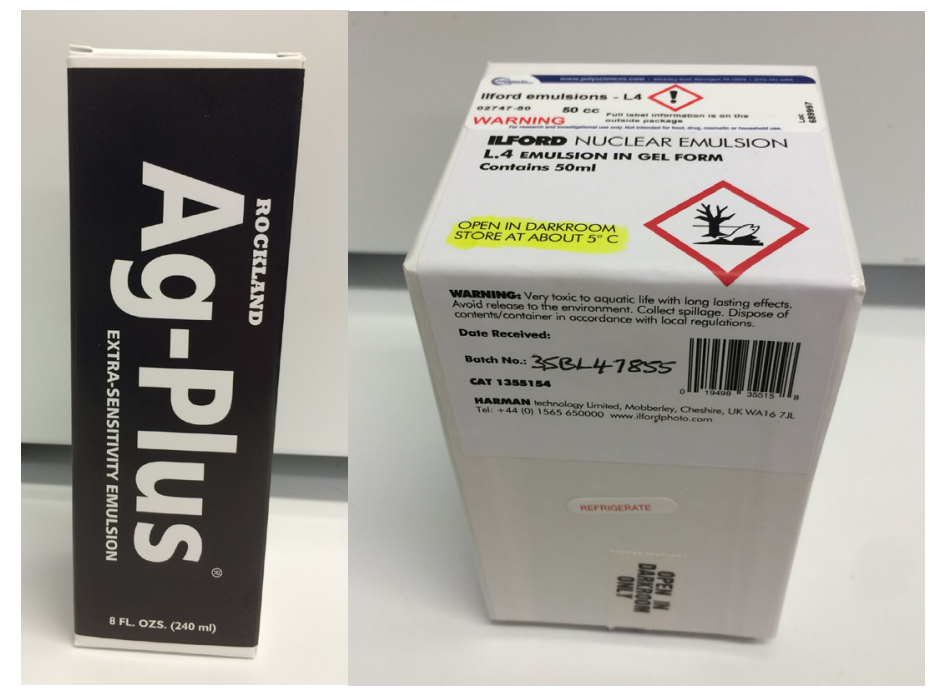

Silver Bromide (AgBr): The silver bromide emulsion used in the experiment was AgPlus from Rockland (left). It is solid at room temperature and needs to be liquefied before it can be added to the emulsion mixture. Make sure to be in a darkroom before opening the AgBr. Other experiments use Ilford L4 emulsion (right). The Ilford emulsion is a lot more expensive, and the Ag-Plus gives good results.

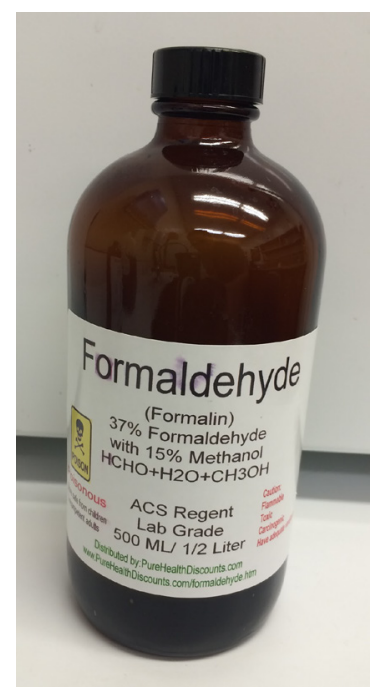

Formalin: Formalin is used to harden the emulsion and make the microprint more permanent. 


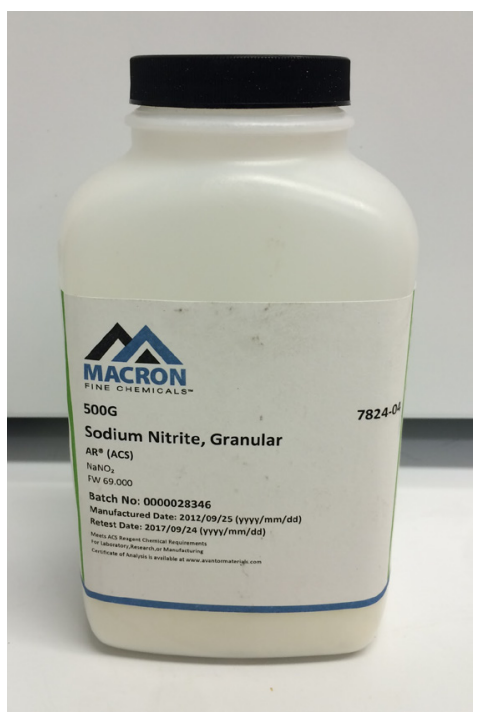

Sodium Nitrite: The sodium nitrite comes in powder form. It helps prevent corrosion, so it is used in both the silver bromide emulsion, and the fixing solution.

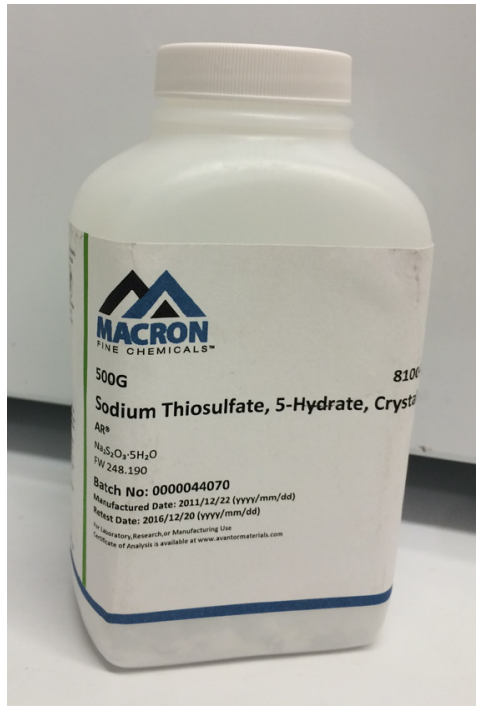

Sodium Thiosulfate: The sodium thiosulfate comes as crystals. The sodium thiosulfate is the main ingredient in the fixer.

\section{A.7 HMT Summary}

This section is intended to be a quick go-to guide for performing HMT. Amounts of each chemical are listed in the tables, and the order of steps is outlined below. 
Table A-2: Sulfuric acid charging solution.

\begin{tabular}{|l|l|l|l|}
\hline Chemical & Distilled Water & Sulfuric Acid $\left(\mathrm{H}_{2} \mathrm{SO}_{4}\right)$ & Thiourea $\left(\mathrm{SC}\left(\mathrm{NH}_{2}\right)_{2}\right)$ \\
\hline Amount & $250 \mathrm{~mL}$ & $6.5 \mathrm{~mL}$ & $0.1 \mathrm{~g}$ \\
\hline
\end{tabular}

Table A-3: Silver bromide emulsion.

\begin{tabular}{|l|l|l|l|}
\hline Chemical & Distilled Water & Sodium Nitrite $\left(\mathrm{NaNO}_{2}\right)$ & Silver Bromide gel $(\mathrm{AgBr})$ \\
\hline Amount & $20 \mathrm{~mL}$ & $2 \mathrm{~g}$ & $10 \mathrm{~g}$ \\
\hline
\end{tabular}

Table A-4: Fixing solution.

\begin{tabular}{|l|l|l|l|}
\hline Chemical & Distilled Water & $\begin{array}{l}\text { Sodium Nitrite } \\
\left(\mathrm{NaNO}_{2}\right)\end{array}$ & $\begin{array}{l}\text { Sodium Thiosulfate } \\
\left(\mathrm{Na}_{2} \mathrm{~S}_{2} \mathrm{O}_{3}\right)\end{array}$ \\
\hline Amount & $20 \mathrm{~mL}$ & $2 \mathrm{~g}$ & $3 \mathrm{~g}$ \\
\hline
\end{tabular}

1. Charge the samples in the acid solution for 2 hours, using a corrosion-resistant plate as the anode and a current density of $0.02 \mathrm{~A} / \mathrm{cm}^{2}$

2. Remove samples from charging bath, rinse with water and methanol, dry with compressed air

3. Allow to sit for desired time

4. Very gentle re-polish to clean sample surface about 15 minutes prior to microprinting

5. Prepare the darkroom- turn on humidifier to $85 \%$, begin warming the $\mathrm{AgBr}$ gel, and measure the chemicals for the fixing solution and emulsion (except $\mathrm{AgBr}$ gel)

6. In the darkroom, add the liquefied $\mathrm{AgBr}$ gel to the emulsion mixture and stir well

7. Apply emulsion to the samples with a wire loop, and allow to develop for 15-20 minutes 
8. After waiting for the full exposure time, dip the sample in formalin for 3 seconds

9. Place sample in the fixing solution with gentle agitation for at least 5 minutes, turn on the lights

10. Clean the sample

1. Place in ultrasonic cleaner with warm distilled water for approximately 5 minutes

2. Add soap to the distilled water bath, continue ultrasonic cleaning for 5 minutes more

3. Rinse with methanol and dry with compressed air

11. Store samples in a vacuum chamber with dessicator to protect against corrosion

12. To clean off after viewing the microprints, let sample sit in warm distilled water, followed by 5 minutes in the ultrasonic cleaner with soapy water, finish with a gentle scrub from a cotton ball. 


\section{APPENDIX B. MATLAB CODE}

This appendix includes the Matlab code used in the analysis of the HMT and EBSD

images for this research.

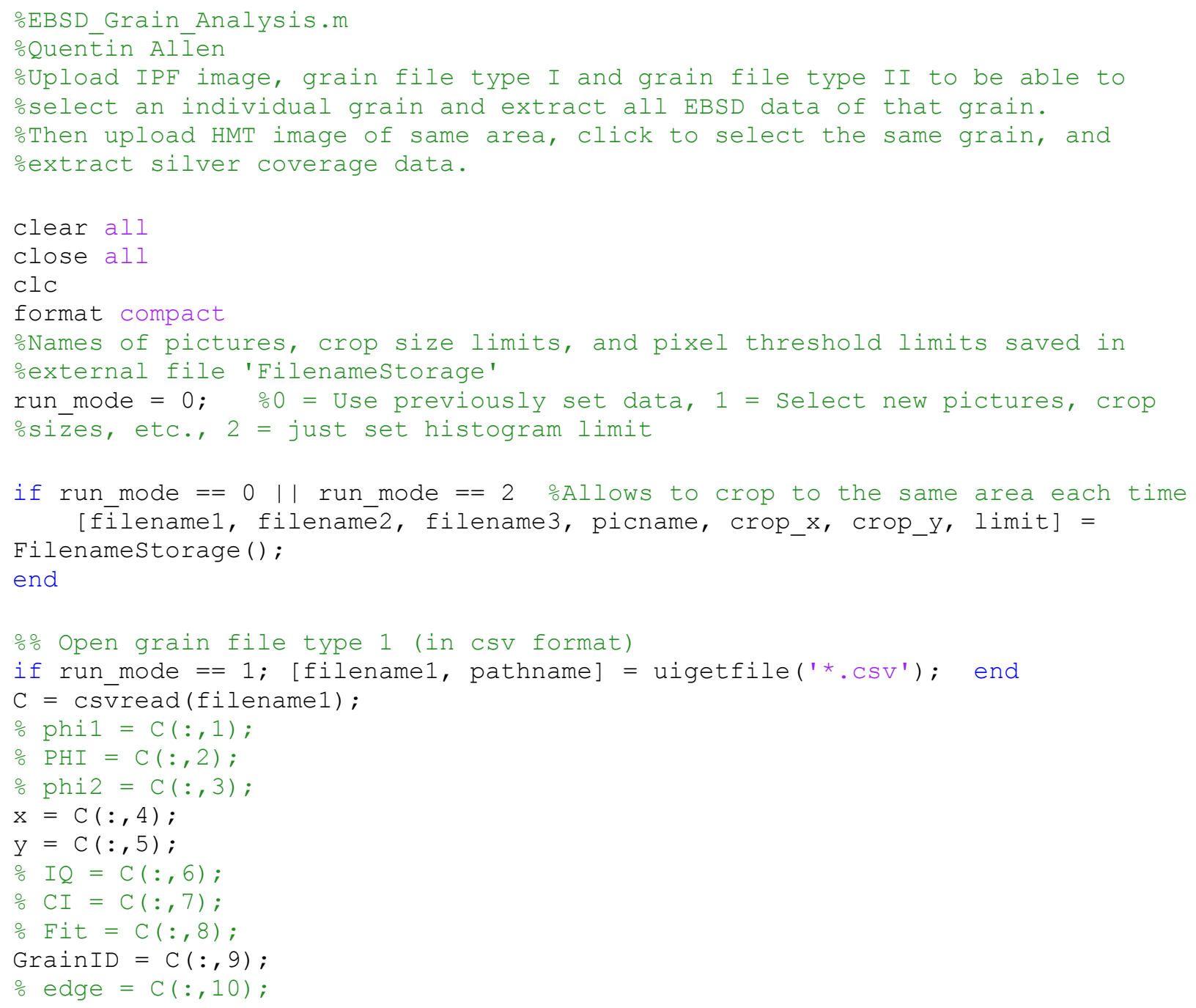




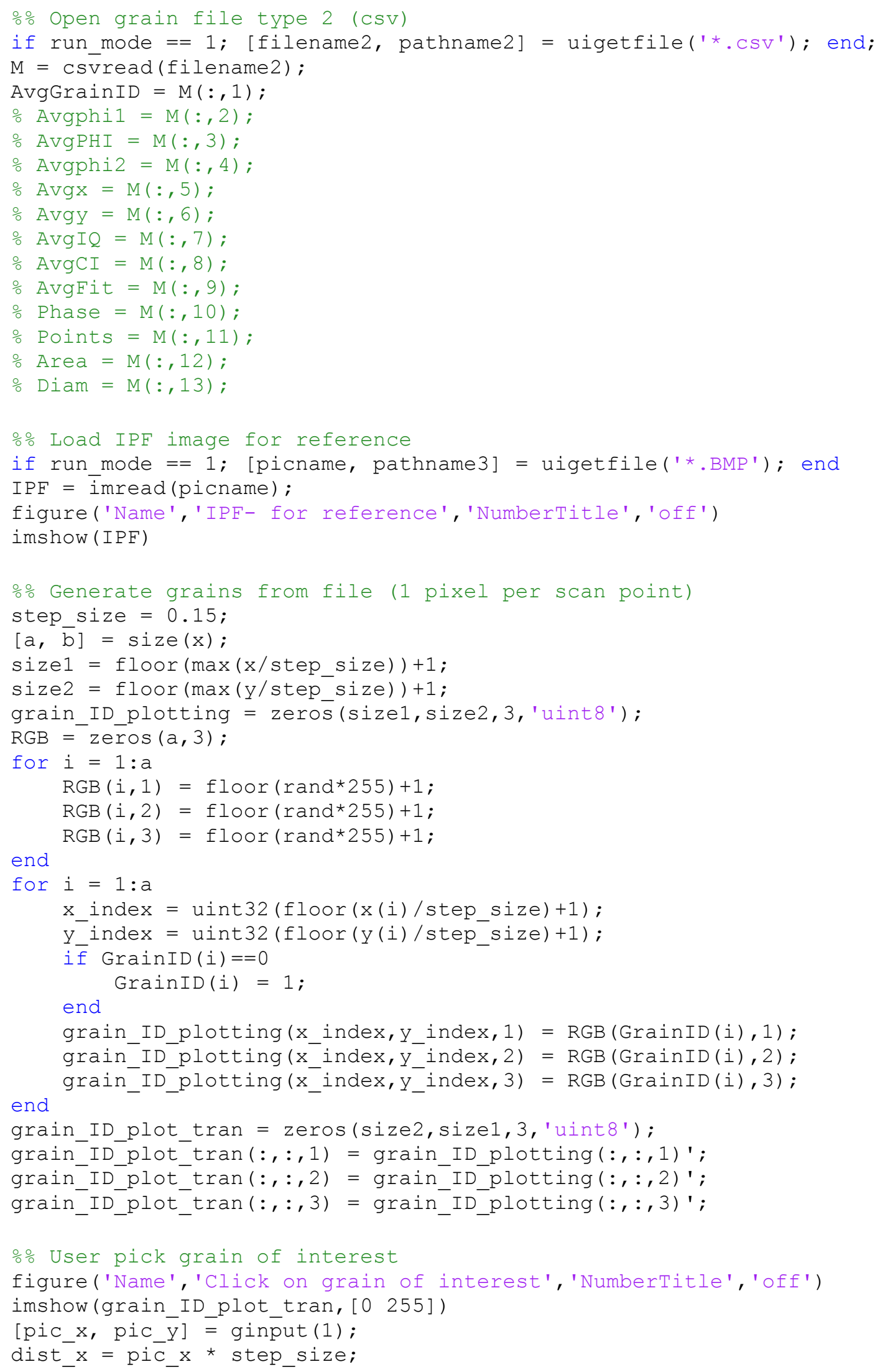




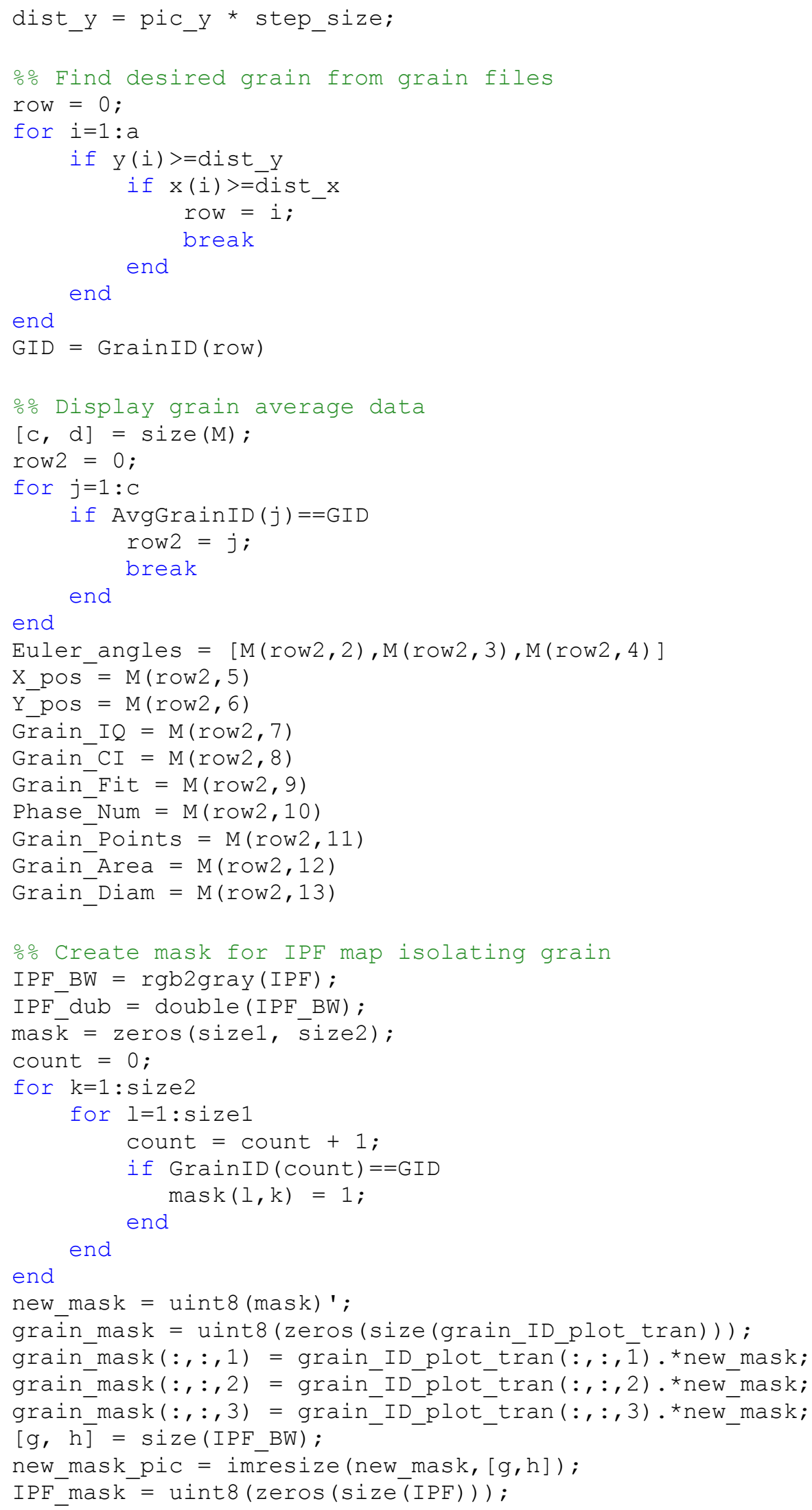




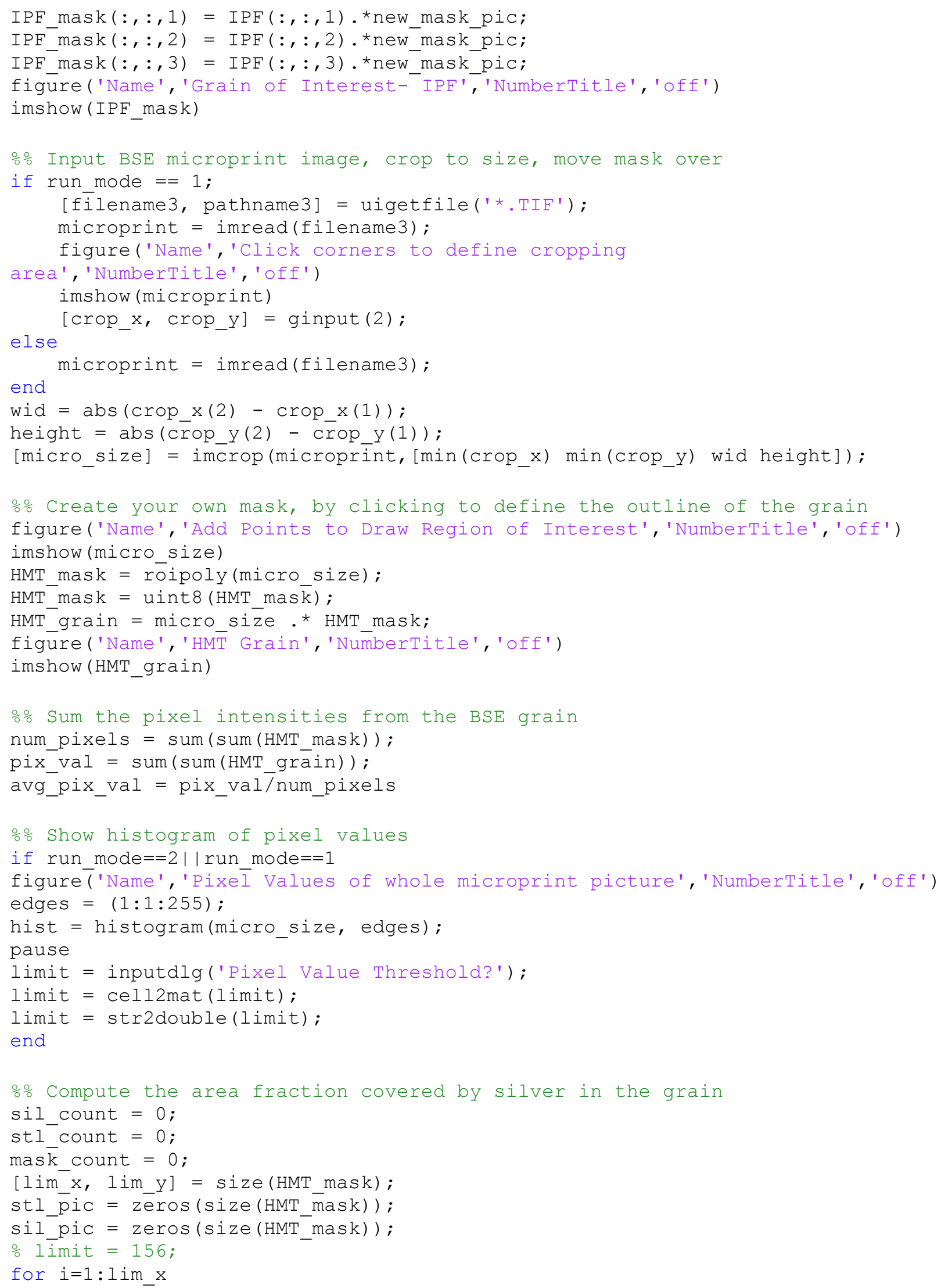




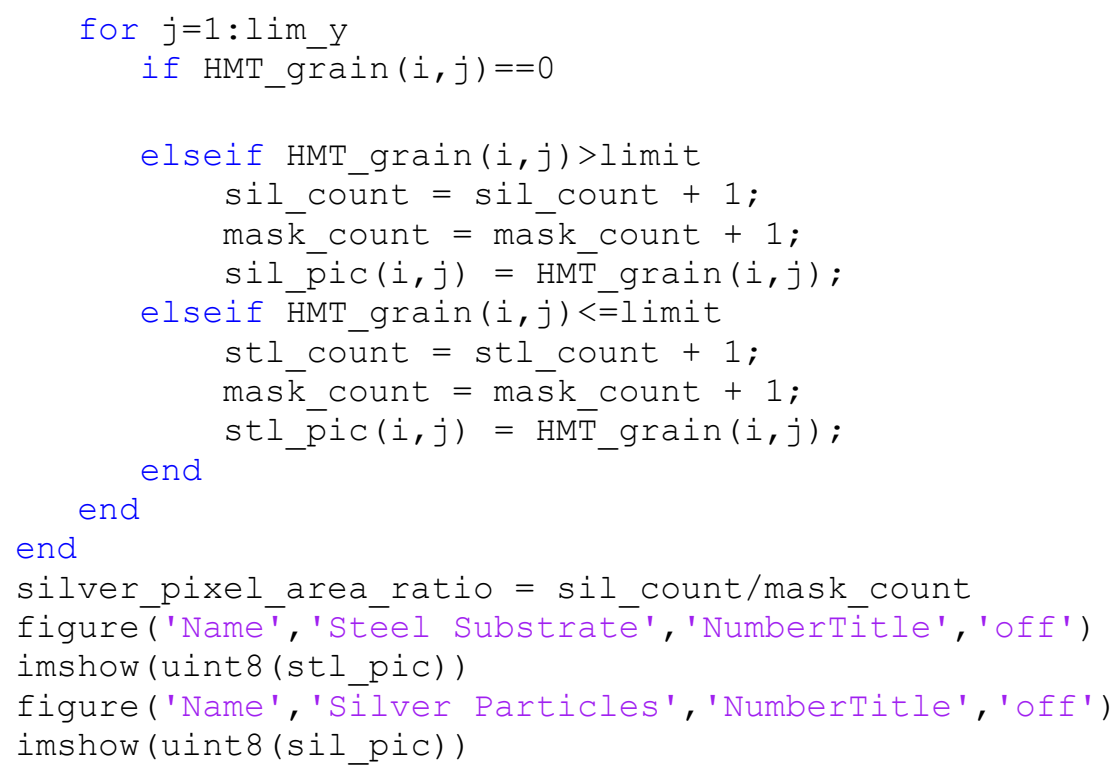

